\title{
Evaluation of an Intervention to Prevent Falls
}

Daniel A. Waxman, Xiaoyu Nie, Asa Wilks, David A. Ganz 
For more information on this publication, visit www.rand.org/t/rr1649

Library of Congress Cataloging-in-Publication Data is available for this publication.

ISBN: 978-0-8330-9662-3

This work was sponsored by the Assistant Secretary for Planning and Evaluation under contract HHSP23320095649WC-TO38, for which Christie Peters serves as project officer.

Published by the RAND Corporation, Santa Monica, Calif.

(C) Copyright 2016 RAND Corporation

RAND $^{\circledR}$ is a registered trademark.

\section{Limited Print and Electronic Distribution Rights}

This document and trademark(s) contained herein are protected by law. This representation of RAND intellectual property is provided for noncommercial use only. Unauthorized posting of this publication online is prohibited. Permission is given to duplicate this document for personal use only, as long as it is unaltered and complete. Permission is required from RAND to reproduce, or reuse in another form, any of its research documents for commercial use. For information on reprint and linking permissions, please visit www.rand.org/pubs/permissions.html.

The RAND Corporation is a research organization that develops solutions to public policy challenges to help make communities throughout the world safer and more secure, healthier and more prosperous. RAND is nonprofit, nonpartisan, and committed to the public interest.

RAND's publications do not necessarily reflect the opinions of its research clients and sponsors.

\section{Support RAND}

Make a tax-deductible charitable contribution at www.rand.org/giving/contribute

www.rand.org 
The Assistant Secretary for Planning and Evaluation (ASPE) advises the Secretary of Health and Human Services on policy development in health, disability, human services, data, and science and provides advice and analysis on economic policy.

ASPE previously commissioned Abt Associates and LifePlans to develop and test an intervention to prevent falls among older Medicare patients. LifePlans conducted a randomized trial of the intervention, enrolling participants (ages 75 and older) between 2008 and 2013. An analysis of that trial, which reached the conclusion that the intervention prevents falls and reduces claims against long-term health insurance, was published in Health Affairs in June 2015 (Cohen et al., 2015). To compare the incidence of falls between the intervention and control groups, the researchers used data collected at quarterly telephone interviews, during which patients were asked to recall falls since the previous interview. ASPE asked the RAND Corporation to perform an independent assessment of the intervention, this time with a focus on outcomes that can be measured objectively using Medicare claims and specifically on health care costs.

ASPE sponsored this work, which was conducted in RAND Health, a division of the RAND Corporation. A profile of RAND Health, abstracts of its publications, and ordering information can be found at www.rand.org/health. 


\section{Contents}

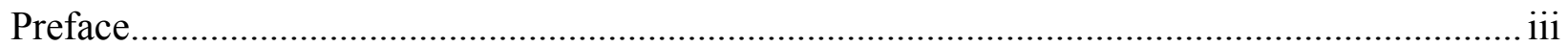

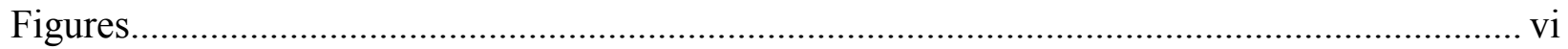

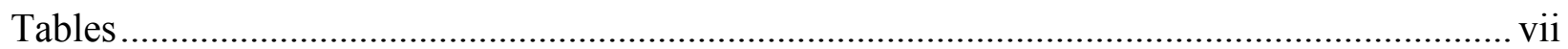

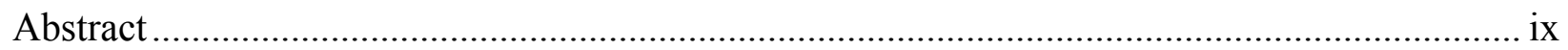

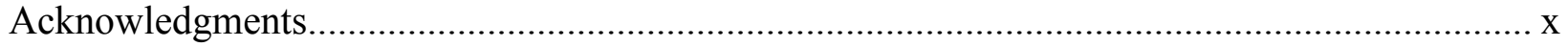

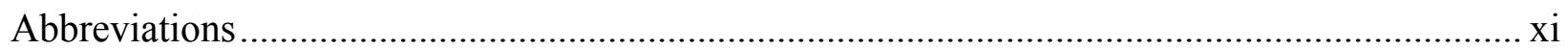

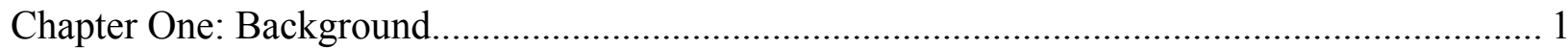

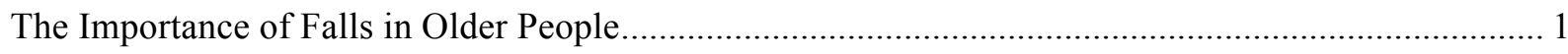

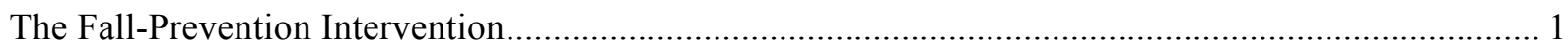

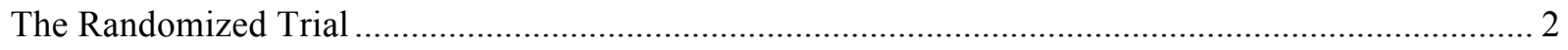

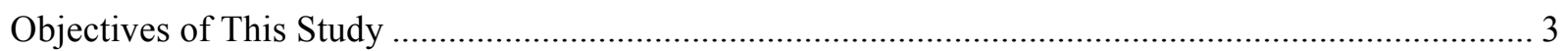

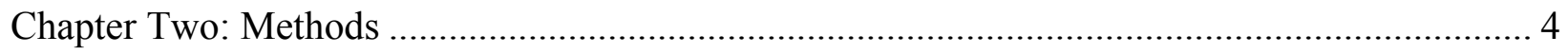

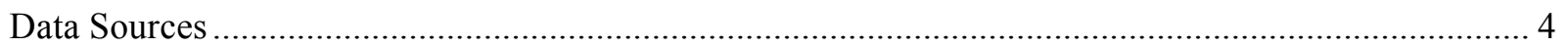

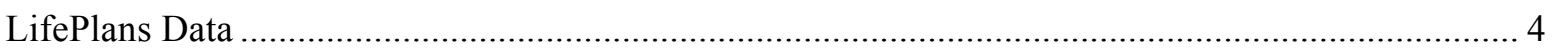

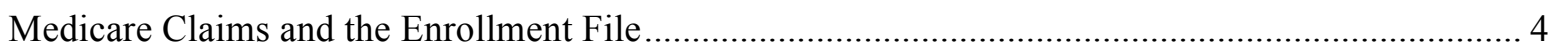

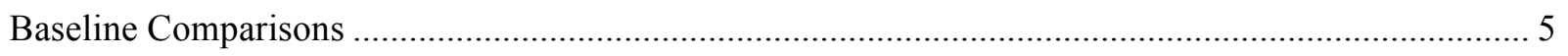

Choice Between an Active Control Group and an Administrative Control Group ............................... 6

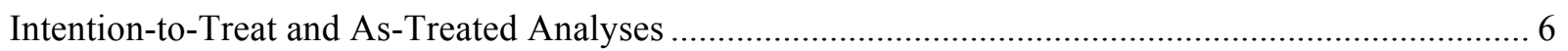

Per-Person, per-Month Comparisons Between Experimental and Control Groups .............................. 6

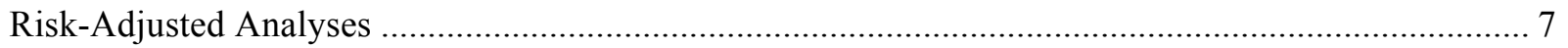

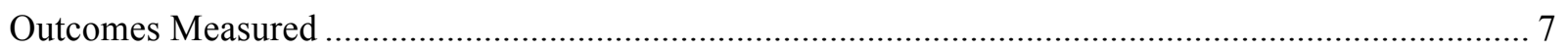

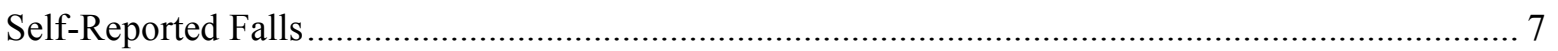

Claims-Based Estimate of the Number of Emergency Department Visits for Fall-Related Injuries... 8

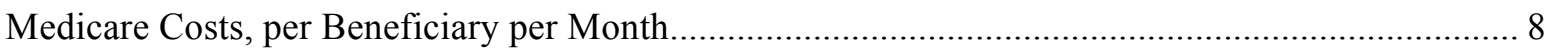

Direct Injury-Related Costs, per Beneficiary per Month ........................................................ 9

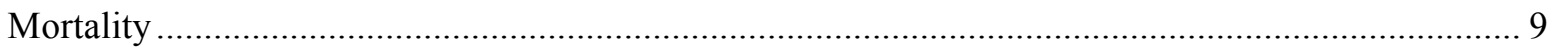

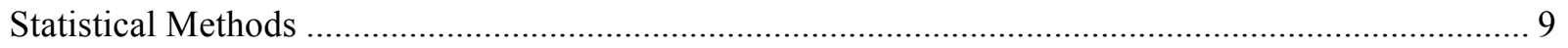

Chapter Three: Populations and Baseline Comparisons ....................................................... 10

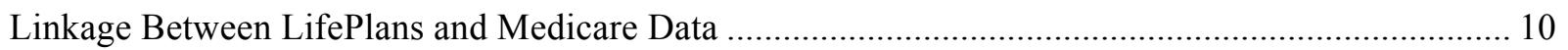

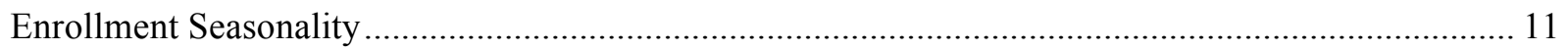

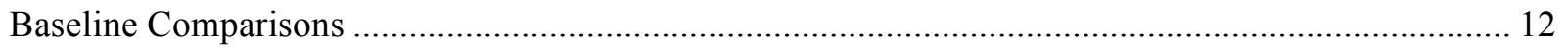

Between Fee-for-Service Medicare Beneficiaries and Others ................................................... 12

Between Those Enrolled Throughout the Intervention Period and Study Dropouts......................... 13

Between Those Randomized to the Experimental Group, the Active Control Group, and the

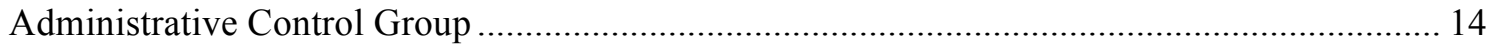

Self-Reported Baseline Information in the Experimental Group Versus the Active Control Group 
Chapter Four: Results: Study Outcomes.............................................................................. 17

Self-Reported Fall Outcomes, As-Treated Population Only .......................................................... 17

Rates of Emergency Department Visits for Fall-Related Injuries, Estimated from Claims.................. 18

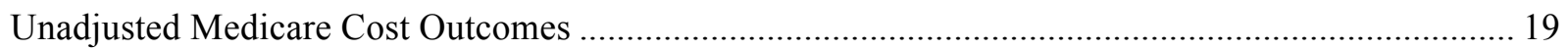

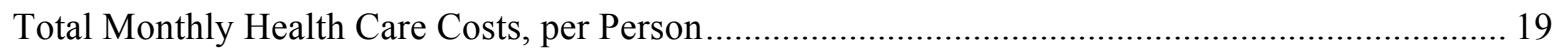

Injury-Related Monthly Health Care Costs, per Person ................................................................... 24

Adjusted Outcomes: Average Treatment Effects ............................................................................. 25

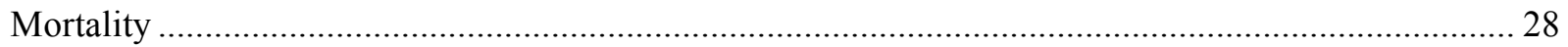

Chapter Five: Discussion ........................................................................................ 30

Appendix A: Model for Identifying Emergency Department Visits for Fall-Related Injuries..... 33

Appendix B: Discussion of Potential Confounders and Remedies......................................... 48

Appendix C: Combining Self-Reported Falls with Published Estimates of Cost Savings per

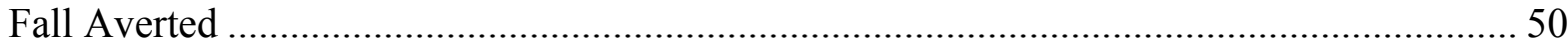

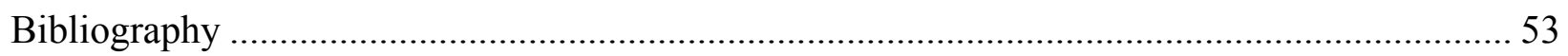




\section{Figures}

Figure 3.1. Histogram of Enrollment into the Study by Calendar Month 12

Figure 4.1. Monthly Costs, One Year Preceding and Following Enrollment: Intention to Treat 20

Figure 4.2. Monthly Costs, Two Years Preceding and Following Enrollment: Intention to Treat..... 21

Figure 4.3. Monthly Costs, One Year Preceding and Following Enrollment: As Treated ........... 22

Figure 4.4. Monthly Costs, Two Years Preceding and Following Enrollment: As Treated......... 23 


\section{Tables}

Table 2.1. Description of Centers for Medicare and Medicaid Services Data Files and Key

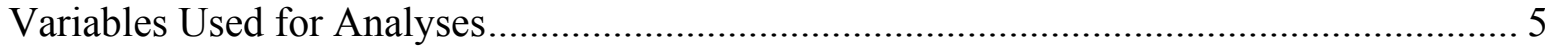

Table 3.1. Linkage of LifePlans Data to Medicare Claims.................................................... 10

Table 3.2. Baseline Comparisons: Matched Fee for Service and Not Fee for Service................ 13

Table 3.3. Baseline Comparisons, Fee for Service, One Year Pre-Enrollment: Dropped Out

Versus Completed Intervention, Patient Characteristics, Group Allocation,

Experimental Group and Active Control Group

Table 3.4. Baseline Comparisons, Fee for Service, One Year Pre-Enrollment: Dropped Out

Versus Completed Intervention, Baseline Medicare Costs and Emergency Department

Visits for Falls, One Year Prior to Enrollment

Table 3.5. Fee-for-Service Population, Baseline Comparisons, Experimental Group Versus

Active or Administrative Control Group.....

Table 3.6. Fee-for-Service Population, Baseline Comparisons, Experimental Group Versus

Active or Administrative Control Group: Number of Emergency Department Visits for

Fall-Related Injuries, Falls per 1,000 Person-Years

Table 3.7. Population Characteristics, Baseline Survey: Experimental Group Versus Active

Control Group, Fee for Service and Others ................................................................... 16

Table 4.1. Self-Reported Falls Among Those Who Completed Four Quarters of Follow-Up:

As Treated.

Table 4.2. Emergency Department Visits for Fall-Related Injuries, Incidence Rates, and

Ratios 19

Table 4.3. Unadjusted Medicare Cost Outcomes, per Person, per Month, by Group 24

Table 4.4. Unadjusted Injury-Related Medicare Cost Outcomes, per Person, per Month, by Group 25

Table 4.5. The Intervention's Estimated Effect on Fall-Related Emergency Department

Visits

Table 4.6. The Intervention's Estimated Effect on Total Medicare Costs, in Dollars per

Month

Table 4.7. The Intervention's Estimated Effect on Medicare Costs for Injury Care, in

Dollars per Month 28

Table 4.8. One- and Two-Year Mortality: Percentage of the Population Matched to

Medicare Record, Including Medicare Advantage

Table 4.9. One- and Two-Year Mortality, Intention-to-Treat Analysis: Percentage of the

Fee-for-Service Population Only 
Table A.1. Model Calibration for In-Sample and Out-of-Sample Predictions of Fall Events Among Emergency Department Visits for Injuries: Observed Versus Predicted Probability, by Risk Decile

Table A.2. Percentage of Injuries That Are Fall-Related (Versus Caused by a Different Mechanism)

Table A.3. Categorization of Probability Mappings from Table A.2 into 20 Quantiles, One for Each Predictor Variable: Principal Diagnosis, 20 Quantiles of Probability

Table A.4. Categorization of Probability Mappings from Table A.2 into 20 Quantiles, One for Each Predictor Variable: First Additional Injury Diagnosis, 20 Quantiles of Probability

Table A.5. Categorization of Probability Mappings from Table A.2 into 20 Quantiles, One for Each Predictor Variable: Second Additional Injury Diagnosis, 20 Quantiles of Probability

Table A.6. Categorization of Probability Mappings from Table A.2 into 20 Quantiles, One for Each Predictor Variable: Sum of Current Injury Probabilities, 20 Quantiles 42

Table A.7. Categorization of Probability Mappings from Table A.2 into 20 Quantiles, One for Each Predictor Variable: Cumulative Previous Emergency Department Injuries, 20 Quantiles

Table A.8. Regression Results for Model of Probability of Fall Conditional on Coded Injury Diagnoses and Patient Characteristics 44

Table C.1. Parameter Values and Estimates for Total Medical Costs per Person 


\section{Abstract}

The Office of the Assistant Secretary for Planning and Evaluation (ASPE) asked the RAND Corporation to evaluate the effectiveness of an intervention designed to prevent falls in the elderly, with a particular focus on fall-related injuries and on health care (Medicare) costs.

We linked data collected during a previously published randomized trial (Cohen et al., 2015) to Medicare enrollment and claims files to compare health care costs and the frequency of fallrelated emergency department (ED) visits between treatment and control groups. Our study design allowed us to make comparisons both before and after trial enrollment and to include patients who dropped out or were lost to follow-up, thereby allowing us to adjust for baseline differences and to perform intention-to-treat analyses.

We did not find a statistically significant effect of the intervention on costs or on the rate of fall-related ED visits. Point estimates (none statistically significant) and 95-percent confidence intervals are as follows: an $\$ 18$-per-month increase (95-percent confidence interval [CI] $=-\$ 94$ to $\$ 130$ ) in total health care spending, an $\$ 18$-per-month increase (95-percent $C I=-\$ 12$ to $\$ 48$ ) for care directly related to injuries, and a 4-percent increase in the risk of falls (95-percent $\mathrm{CI}=26$-percent decrease to 43-percent increase). We conclude that the fall-prevention intervention did not have a substantial effect on health care costs. Although we did not find evidence that the intervention reduced ED visits for fall-related injuries, imprecision of our estimates means that a clinically meaningful effect could have gone undetected. 


\section{Acknowledgments}

We thank Helen Lamont and William Marton from the Office of the Assistant Secretary for Planning and Evaluation for providing guidance and strategic direction. We are also grateful to Jessica Miller, Xiaomei Shi, and Marc A. Cohen from LifePlans for providing data and thoughtful advice. 


\section{Abbreviations}

$\begin{array}{ll}\text { ACG } & \text { active control group } \\ \text { ADCG } & \text { administrative control group } \\ \text { ASPE } & \text { Assistant Secretary for Planning and Evaluation } \\ \text { CI } & \text { confidence interval } \\ \text { CMS } & \text { Centers for Medicare and Medicaid Services } \\ \text { DME } & \text { durable medical equipment } \\ \text { E-code } & \text { external-cause-of-injury code } \\ \text { ED } & \text { emergency department } \\ \text { EG } & \text { experimental group } \\ \text { FFS } & \text { fee for service } \\ \text { ICD-9 } & \text { International Classification of Diseases, } 9 \text { th edition } \\ \text { MA } & \text { Medicare Advantage } \\ \text { MEDPAR } & \text { Medicare Provider Analysis and Review } \\ \text { SCI } & \text { spinal-cord injury } \\ \text { SD } & \text { standard deviation } \\ \text { SE } & \text { standard error } \\ \text { TBI } & \text { traumatic brain injury } \\ \text { VCI } & \text { vertebral-column injury } \\ & \end{array}$


The Importance of Falls in Older People

Falls are a common occurrence in older people, with about one-third of community-dwelling people ages 65 and older falling at least once during the year. Although most falls do not result in injury, 5 to 10 percent of people who fall have serious injuries, including fractures, head trauma, or lacerations requiring closure. These injuries can lead to a loss of ability to carry out some of life's daily tasks or, in the most-severe cases, a loss of ability to care for oneself. Adjusted to 2008 dollars, fall injuries have been estimated to cost $\$ 23.3$ billion annually in the United States (Davis et al., 2010).

Given the morbidity associated with serious fall injuries, researchers have conducted numerous studies attempting to reduce falls in older people (Gillespie et al., 2012). Exercise programs have been shown to reduce falls, and individually tailored multifactorial assessment and intervention could reduce falls, although the strength of the evidence is weaker than that for exercise. Individually tailored multifactorial assessment involves assessing an older patient to see which of the different risks for falls (e.g., balance problems, visual impairment, and polypharmacy) are present in that person and then intervening on the specific risks that are uncovered.

One limitation of some of the studies on reducing falls carried out to date are the variety of inclusion and exclusion criteria applied and, in some cases, the fact that the studies are carried out in academic settings or with referral populations. There is a need for more-pragmatic studies enrolling a broad swath of older people through a mechanism that could easily be replicated routinely. The fall-prevention intervention detailed in the next section is an example of a pragmatic study.

\section{The Fall-Prevention Intervention}

In fiscal years 2004 and 2005, the Office of the Assistant Secretary for Planning and Evaluation (ASPE) contracted with Abt Associates and LifePlans to develop a multifactorial fallprevention program. The intervention that they developed consisted of four components: (1) a nurse-delivered in-home assessment of fall history, health and medication information, functional status, environmental risk factors, and gait and balance; (2) a customized action plan and a fall-prevention and wellness toolkit mailed to each participant based on the assessment, with assessment findings and a guide to their interpretation also sent to the participant's primary care physician; (3) a nurse-delivered follow-up coaching phone call within two weeks of the 
action plan being delivered to the participant; and (4) a quarterly newsletter with additional coaching and educational materials delivered over the course of one year.

\section{The Randomized Trial}

LifePlans designed a randomized controlled trial of this intervention, enrolling patients between 2008 and 2013. Notably, it recruited enrollees from a pool of people ages 75 and older who had purchased long-term care insurance, held their policies for at least five years, and had no long-term care insurance claim at the time of study enrollment.

The researchers randomized trial participants into one of three arms: the experimental group (EG), an active control group (ACG), and an administrative control group (ADCG). Members of the EG and ACG received quarterly follow-up phone calls to collect data on falls and fall-related outcomes, such as injuries and seeking medical attention after a fall. Participants in the ADCG consented to have their long-term care and Medicare claims evaluated (as was also the case for the EG and ACG) but were not contacted after the initial study enrollment. ADCG was chosen as an additional control group to account for the possibility of a Hawthorne effect - that the quarterly phone calls would themselves have an effect on study outcomes.

A study published in Health Affairs in June 2015 reported results of the randomized trial (Cohen et al., 2015). Initially, 2,839 patients were assigned to the EG, 2,471 to the ACG, and 1,919 to the $\mathrm{ADCG}$, and the numbers who received their allocated interventions were 1,813 (EG), 2,025 (ACG), and 1,919 (ADCG). The trial was evaluated from an as-treated perspective, meaning that the analyses included only those patients who remained enrolled throughout the intervention period. Of those whose outcomes were measured, patients in the EG were reported to have had fewer falls overall and fewer falls resulting in injury (measured by self-report during quarterly follow-up calls), during each of the first four quarters of follow-up, than those in the ACG. ${ }^{1}$ At the end of four quarters, the EG was associated with a relative risk of falls of 0.89 (95percent confidence interval $[\mathrm{CI}]=0.79$ to 1.00$)$ and a relative risk of injurious falls of 0.82 (95percent $\mathrm{CI}=0.71$ to 0.96 ). Another key finding was that patients randomized to the intervention had 33-percent fewer claims for long-term care services, such that, by virtue of lower long-term care costs, the intervention resulted in a net cost savings of $\$ 1.68$ for every $\$ 1.00$ spent.

Principal limitations of the published study were that the intervention's effect on health care spending could not be measured and that potential bias associated with higher dropout rates in the EG could not be fully assessed. A reliance on self-reported data on falls also meant that the ADCG could not be used as a comparison group for falls (because its members did not receive follow-up calls) and that estimates were subject to recall bias.

\footnotetext{
${ }^{1}$ The authors did not compare falls between EG and ADCG members because the ADCG did not receive the quarterly telephone calls that were used to measure them.
} 


\section{Objectives of This Study}

This study was designed to complement the previous one - to evaluate the effect of the intervention using Medicare claims as an objective measure of costs and health care utilization among the subset of study participants who were enrolled in the Medicare fee-for-service (FFS) program. Whereas Cohen et al. evaluated the intervention's effect on costs for long-term care insurance claims (an outcome we do not consider here), a principal goal of this study was to determine whether the intervention reduced health care (Medicare) spending, a question that responds to congressional interest in evaluating the cost-effectiveness of fall-prevention interventions for the elderly. Although many worthwhile interventions are not cost-saving, we recognized that, if this particular intervention were found to pay for itself by reducing costly care for fall-related injuries, there would be very strong justification for including it as a covered service under the Medicare program.

Besides the goal of determining the intervention's cost implications, linking the data from the randomized trial to Medicare claims provided the opportunity to overcome certain inherent limitations of the previous analysis - particularly, the problem of selective dropout of patients assigned to the EG. It also allowed us to develop and implement an objective measure of emergency care for fall-related injuries, meant in part as a surrogate for falls themselves. Such a measure is desirable because self-report is known to be an imperfect reference standard for fallprevention interventions. 


\section{Chapter Two}

Methods

We linked data from the randomized trial to Medicare enrollment and claims data. The linkage allowed us to compare costs and health care utilization across the three study groups (EG, ACG, and ADCG) and to make those comparisons both before and after enrollment in the randomized trial. Using Medicare claims, we developed and validated a method to identify and quantify emergency department (ED) visits for acute fall-related injuries. Using this method and the linked data, we were able to compare baseline populations to assess the randomization process and, more importantly, to evaluate the trial results from an intention-to-treat perspective, thereby circumventing the potential problem of selective dropout.

Because Medicare claims are available only for beneficiaries enrolled in traditional FFS Medicare, we restrict our analyses of claims-based outcomes to the subset of original study enrollees who were identified as participants in that program at the time of study enrollment.

\section{Data Sources}

\section{LifePlans Data}

LifePlans provided data to RAND on 7,178 subjects: 2,809 in the EG, 2,451 in the ACG, and 1,918 in the ADCG. Approximately 19 percent of those enrolled in the EG dropped out before completing the intervention, whereas only 7 percent of those in the ACG did.

LifePlans included each participant's randomly assigned group, enrollment date, age, and Social Security number in an enrollment file, which contained a record for each study participant. For those in the EG and ACG who did not drop out, information from a baseline assessment and quarterly follow-up calls was also available. The baseline assessment included additional demographic information, as well as patient responses to questions regarding the number of recent falls and injuries and regarding baseline functional status. The quarterly followup telephone calls included information on the number of falls the participant had experienced in the quarter. Unless a participant dropped out during the follow-up period, we followed each participant for at least four quarters after enrollment.

\section{Medicare Claims and the Enrollment File}

We performed all analyses involving Medicare data using the Virtual Research Data Center, a secure environment for Medicare claims analysis. We uploaded study data from LifePlans to the data center. We requested a crosswalk between the study participants' Social Security numbers and their Medicare beneficiary identification numbers from the Centers for Medicare and Medicaid Services (CMS). Using that crosswalk, we linked each LifePlans record to a 
unique Medicare beneficiary identifier and thereby linked to the Medicare data of interest (see Table 2.1).

Table 2.1. Description of Centers for Medicare and Medicaid Services Data Files and Key Variables Used for Analyses

Study Objective or Measure

Identify patient demographics and MA enrollment status.

Identify utilization and costs of inpatient and skilled nursing facility care.

Identify utilization and costs of outpatient care.

Identify costs of doctor visits.

Identify utilization and costs of home health care.

Identify costs of DME.

Identify costs of hospice care.

\section{CMS Data Files Used}

Master Beneficiary Summary Files (base segment) for 2006-2014 (see Research Data Assistance Center, undated [e])

MEDPAR files for 2006-2014 (see CMS, 2015)

Outpatient files for 2006-2014 (see Research Data Assistance Center, undated [f])

Carrier files for 2006-2014 (see Research Data Assistance Center, undated [a])

Home Health Agency files for 2006-2014 (see Research Data Assistance Center, undated [c])

DME files for 2006-2014 (see Research Data Assistance Center, undated $[b]$ )

Hospice files for 2006-2014 (see Research Data Assistance Center, undated $[\mathrm{d}]$ )

NOTE: MA = Medicare Advantage. MEDPAR = Medicare Provider Analysis and Review. DME = durable medical equipment.

\section{Baseline Comparisons}

Like with any randomized controlled trial, random chance, selective dropout, or an inadvertent malfunction of the randomization process can cause group-level baseline differences that could affect a study outcome, causing the treatment effect to appear smaller or larger than it actually is. To explore the possibility of such confounding, we compared the EG, ACG, and ADCG according to age at study enrollment, sex, and Medicare costs and the number of fallrelated ED visits in the 12 and 24 months prior to study enrollment.

To determine whether non-random selection of the original enrollees into the final analytic samples introduced baseline differences, we compared baseline characteristics between those who matched to a FFS Medicare enrollment record and those who did not match and between those for whom the intake and intervention process was completed versus those who dropped out before the start of LifePlans quarterly follow-up calls. We also explored the potential for seasonality or secular trend to cause spurious associations. 


\section{Choice Between an Active Control Group and an Administrative Control Group}

In our pre-specified analytic plan, we designated the ACG to be the primary comparison group, with the rationale that quarterly follow-up calls (to which both the EG and ACG were exposed) constituted a kind of intervention in and of itself but would probably not be part of the implementation plan if the intervention were widely adopted. Thus, the EG-versus-ACG comparison would effectively "average out" the effect of the follow-up calls and provide the truest measure of the effect of the intervention itself. We also specified that we would secondarily compare EG and ADCG to measure the combined effect of the actual intervention and the quarterly follow-up calls.

\section{Intention-to-Treat and As-Treated Analyses}

The intention-to-treat analyses compare outcomes among all included patients who initially enrolled in the study, regardless of whether or not they dropped out prior to the start of the observation window (i.e., after completing the intervention [EG] or after completing the initial phone interview [ACG]; for ADCG, the intention-to-treat and as-treated populations were the same). We defined the observation window as the period over which LifePlans asked participants during quarterly telephone calls to recall how many times they had fallen. To eliminate confounding by selective dropout, we pre-specified that we would use intention to treat as our primary analytic perspective. This decision was affirmed with recognition that seasonal effects, time shifts in the observation window, and a late increase in the proportion of randomized patients allocated to the experimental group were also potential confounders to as-treated analyses. Nevertheless, because self-reported outcomes are available only for those who remained enrolled, we also present results from the as-treated perspective.

The choice between intention to treat and as treated involves inherent trade-offs: Intention-totreat analyses understate the magnitude of effect on those who actually receive the intervention but are less subject to confounding. The intention-to-treat perspective also reflects the reality that not all patients targeted for an intervention will receive it and could offer a more practical measure of a program's potential impact.

\section{Per-Person, per-Month Comparisons Between Experimental and Control Groups}

We compare the average between-group difference in claims-based outcomes (fall-related ED visits and Medicare costs, discussed later) across all months in which a patient remained alive and enrolled in the FFS program at one and two years after study enrollment (intention to treat) or at the end of the intervention period (as treated). Patients who died or switched out of the FFS program before the end of the time frame of interest contribute to the overall results with 
proportionally less weight. Because there was a substantial delay between enrollment and the end of the intervention period (more so for those assigned to the EG), late enrollment meant that a substantial number of EG participants had two-year as-treated observation windows that extended beyond the limits of our available data (which covered claims through calendar year 2014). To remedy this problem, for the two-year (but not the one-year) analyses, we considered only participants who enrolled prior to October 1,2012, thereby ensuring that most patients in the as-treated group had complete data.

\section{Risk-Adjusted Analyses}

Because we found differences between the EG and the control groups in pre-enrollment Medicare costs and in the timing of study enrollment (EG patients had higher baseline costs and were randomized in later years, on average), we used a difference-in-differences approach to estimate the intervention's effect after adjusting for potential confounders. Using data organized as one observation per person per calendar month, we modeled Medicare costs and the number of fall-related ED visits as a function of a treatment-group variable, which we define as the interaction between two other variables that are also in the model-indicators for an individual's assignment to the EG and for a post-enrollment (versus pre-enrollment) observation - as well as an indicator for sex and linear terms for age and for the calendar year of the observation. We fit separate models for the EG versus the ACG and for the EG versus the ADCG, estimating the average treatment effect at up to 12 and 24 months after enrollment (for each person, we used up to 24 and 48 months of data - an equal number of pre-enrollment and post-enrollment months). We used linear regression to model costs and Poisson regression to model the number of fallrelated ED visits using standard errors clustered by person in both cases. We also tested other models and found that all of those that controlled for baseline costs yielded similar results.

\section{Outcomes Measured}

\section{Self-Reported Falls}

Although the primary focus of this study was on outcomes that we could measure in Medicare claims, we also compared the relative incidence of falls as self-reported during the quarterly telephone calls - an analysis that paralleled one previously reported (Cohen et al., 2015). Specifically, to calculate the incidence rate, we divided the total number of falls that participants experienced in a given quarter by the total elapsed time that participants experienced during the quarter. Differences between the results reported here and those published previously might be attributable to our inclusion of additional participants for whom data were not previously available.

Incidence rates reflect cumulative falls reported in each of four quarterly follow-up telephone interviews. Incidence rate ratios represent the incidence rate in the EG divided by the incidence 
rate in the ACG. We use exact tests to assess the statistical significance of any differences; in addition, 95-percent CIs are generated around the incidence rate ratio to provide a range of uncertainty around the observed effect.

\section{Claims-Based Estimate of the Number of Emergency Department Visits for Fall-Related Injuries}

We chose to focus on a claims-based estimate of ED visits for fall-related injuries because the entry point to care of most serious fall injuries (those that constitute the bulk of health care costs for falls) is through the ED. We used a prediction model to weight ED visits based on the likelihood that the injuries diagnosed were caused by falls (see Appendix A) because not all claims for injuries specify the mechanism of injury. For example, if a given set of diagnoses and patient characteristics predicted that injuries coded in a given ED visit had a 92-percent probability of having been caused by a fall, we gave it a weight of 0.92 . If a different visit were predicted to have a 64-percent probability of having been caused by a fall, we gave it a weight of 0.64. We then summed these weights to obtain the total number of predicted falls in each study arm (group) and compared these totals by study arm using the same approach detailed above for total Medicare costs.

\section{Medicare Costs, per Beneficiary per Month}

We defined our primary cost outcome (total Medicare costs) as the aggregate of payments made (or owed) for all health care services that the FFS program covers. ${ }^{2}$ This includes payments by Medicare or other insurance and what Medicare considers the beneficiary's payment responsibility (where applicable). We included claims found in the following standard analytic files: MEDPAR, outpatient, carrier, DME, home health, and hospice. We did not include Part D claims. ${ }^{3}$ To facilitate the risk-adjusted analysis, we aggregated all costs by person and calendar month, and we report all costs as monthly. Our primary cost outcome was total costs for all Medicare services.

We found the distribution of total costs to be markedly skewed, to the extent that, in our finite samples, unequal distribution of a few high-cost outliers could confound results. We therefore tested the effect of casewise deletion of those with spending beyond the 99th percentile. We found that such truncation did not have a meaningful effect on results, so the results presented here use the full sample. Our risk-adjustment method would also be expected to largely control for cost outliers.

\footnotetext{
2 Our claims-based analyses are necessarily restricted to FFS because claims are not available for others.

3 Although the fall-prevention intervention could have affected prescription drug use, we felt that the changing landscape of Part D enrollment over the time frame of the study would limit our ability to make valid inferences using Part D claims.
} 


\section{Direct Injury-Related Costs, per Beneficiary per Month}

In addition to total costs, we evaluated the effect of the intervention on direct injury-related Medicare costs, which we defined as the subset of claims for which one or more diagnosis fields indicated an injury, as defined by the following ranges of International Classification of Diseases, 9th ed. (ICD-9) codes: 800 to 904,910 to 929, 940 to 957, and 959. These codes represent all ICD-9 codes for injuries, excluding late effects (905-909), foreign bodies (930939), and traumatic complications (958).

We intended this measure as a proxy for all fall-related costs, recognizing that not all injuries are fall-related, that this method might miss indirect costs (e.g., hip fracture leading to pulmonary embolism), and that it might overcount costs for which the injury is not the primary problem (e.g., hospitalization for an arrhythmia that led to dizziness and a fall, which resulted in a wrist fracture).

\section{Mortality}

Using mortality information in Medicare data, we compared mortality across study arms. Although the study was not powered to detect mortality differences, if we found differences, we would need to interpret with caution the results as they pertain to other outcomes.

\section{Statistical Methods}

Unless otherwise noted, $p$-values reflect the results of $t$-tests for comparisons of group means, and chi-square tests for comparisons of proportions. Standard errors and CIs for data accumulated at a per-person, per-month level are adjusted for clustering within individuals. 
In this chapter, after reporting on the linkage between study data and CMS enrollment files, we perform some baseline comparisons - that is, we compare various characteristics across populations defined by the original randomization process, the linkage to Medicare and the FFS requirement, and by study dropout versus continued enrollment. These comparisons are meant to identify potential biases, to inform our understanding of the intention-to-treat versus as-treated perspectives, and to determine the potential need for risk-adjusted estimates of the intervention's effect.

\section{Linkage Between LifePlans and Medicare Data}

Among the 7,178 people in the LifePlans data, 6,952 (97 percent) matched to Medicare records (the Master Beneficiary Summary File) (Table 3.1).

Table 3.1. Linkage of LifePlans Data to Medicare Claims

\begin{tabular}{lcc}
\hline Data & $\boldsymbol{N}$ & Percentage \\
\hline No match to Medicare enrollment file & 226 & 3 \\
MA & 1,734 & 24 \\
FFS Medicare without Part B (excluded) & 83 & 1 \\
FFS Medicare & 5,135 & 72 \\
Total LifePlans population & 7,178 & 100 \\
\hline
\end{tabular}

NOTE: MA versus FFS designations are based on whether the patient was enrolled in FFS for at least three months before and three months after enrollment in the LifePlans study. 
Of the 6,952 people who matched, 1,734 were enrolled in MA as of the month of study recruitment or within three months before or after. ${ }^{4}$ Also, 83 FFS beneficiaries were enrolled in Medicare Part A but not Part B. The remaining 5,135 people make up our primary study (intention-to-treat) population - they represent all those originally recruited into the randomized trial whose care was observable using Medicare claims. They were distributed across the following groups: ${ }^{5}$

- 1,985 in the EG (71 percent of those originally randomized to the EG)

- 1,786 in the ACG (73 percent of those originally randomized to the ACG)

- 1,364 in the ADCG (71 percent of those originally randomized to the ADCG).

Of the 1,985 in the EG, 366 people (18 percent of the total) had dropped out prior to completing the fall-prevention intervention according to LifePlans records. Of those in the ACG, 120 people ( 7 percent) dropped out prior to their designated start-of-observation dates. We therefore excluded these 486 people from the as-treated analysis. ${ }^{6}$

\section{Enrollment Seasonality}

There was a strong seasonality to enrollment, which occurred over a multiyear time span. As shown in Figure 3.1, peak enrollment occurred in the months of October and November.

\footnotetext{
${ }^{4}$ The choice of three months was an arbitrary one, meant to enforce the requirement that each patient had at least some baseline data and some post-enrollment data. A large majority of patients who were enrolled in FFS at the time of study enrollment remained enrolled in FFS through the one- and two-year follow-up windows or until they died. ${ }^{5} p=0.19$ for Fisher's exact test for independence between study arm and FFS match (i.e., consistent with random assignment).

${ }^{6}$ The intention-to-treat and as-treated populations also differ slightly because the as-treated analysis starts later (completion of intervention versus study enrollment) and the insurance status of a small number of patients changed in the interim.
} 
Figure 3.1. Histogram of Enrollment into the Study by Calendar Month

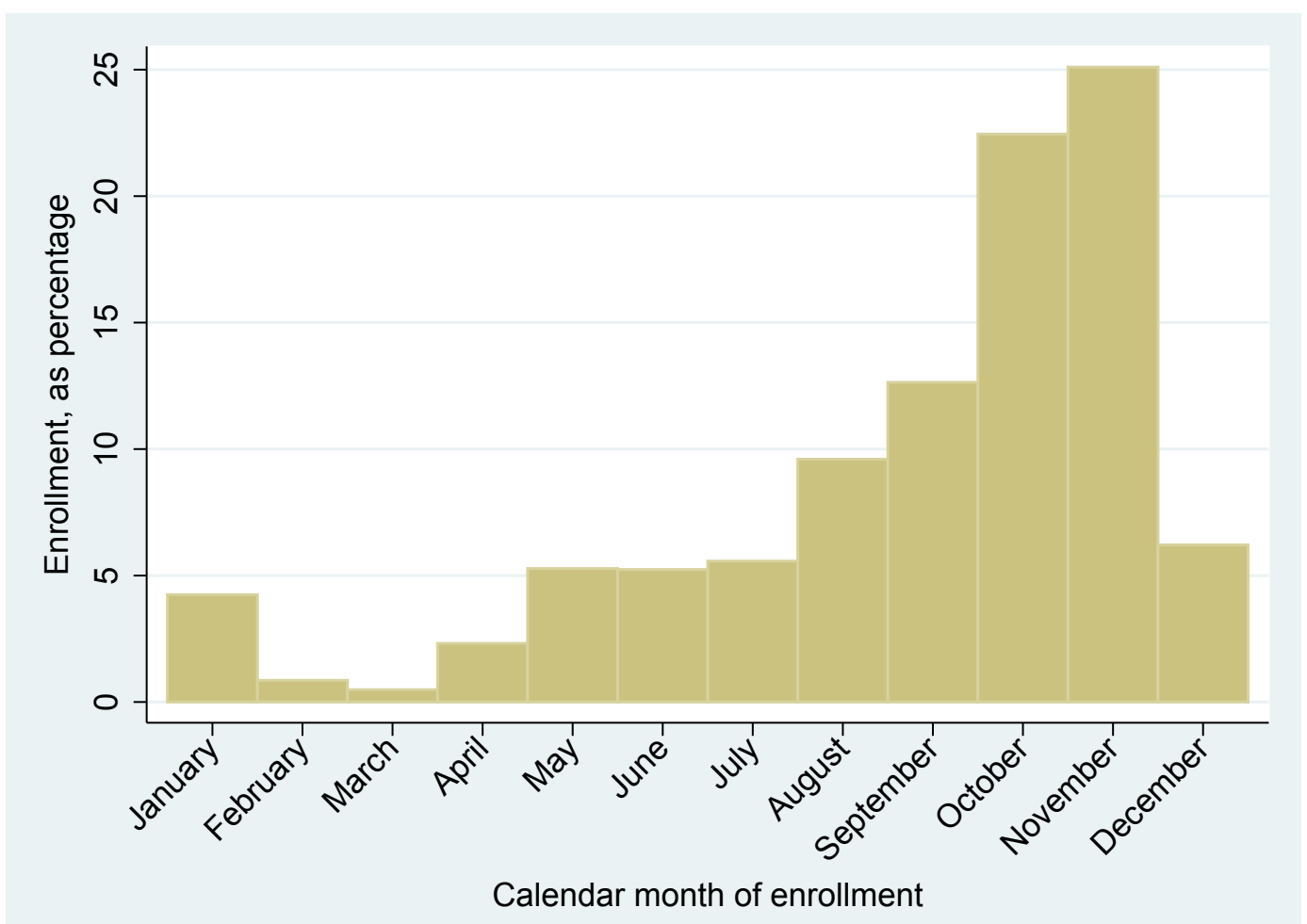

In addition, the elapsed time between enrollment and the start of the observation period, defined as the period in which participants were asked to recall their falls on a quarterly basis, was longer for the EG than for the ACG (data not shown).

\section{Baseline Comparisons}

In the following tables, we compare baseline measurements and characteristics across various dimensions of the data: For example, we compare age and randomization group assignment between those who matched to FFS records and those who did not. We compare age, sex, rates of falls, and monthly Medicare costs between those who remained enrolled throughout the intervention period and those who dropped out. We compare patients randomized to the EG, ACG, or ADCG according to the same characteristics as for dropouts versus non-dropouts but also according to a more detailed set of questions asked during the baseline interview. In each case, what we compared is what was available for both sides of the comparison (e.g., baseline costs could be measured only for FFS beneficiaries and so could not be compared in Table 3.2).

\section{Between Fee-for-Service Medicare Beneficiaries and Others}

Table 3.2 shows a baseline comparison of those who matched to FFS Medicare data and others. Those matching to FFS Medicare were slightly older ( 80.9 versus 80.7 years of age), but 
the proportion allocated to study arms did not differ between those who matched to FFS Medicare and others.

Table 3.2. Baseline Comparisons: Matched Fee for Service and Not Fee for Service

\begin{tabular}{lcc}
\hline Characteristic & FFS at Enrollment $(\boldsymbol{N = \mathbf { 5 } , \mathbf { 1 3 5 } )}$ & Not FFS $(\boldsymbol{N}=\mathbf{2 , 0 4 3})$ \\
\hline Mean age, in years $(p=0.05)$ & 80.9 & 80.7 \\
$\quad$ SD & 3.9 & 3.9 \\
Percentage randomized to study arm $(p=0.188)$ & & 40 \\
EG $(N=2,809)$ & 39 & 33 \\
ACG $(N=1,786)$ & 35 & 27 \\
ADCG $(N=1,364)$ & 27 & 100 \\
Column total & 100 &
\end{tabular}

NOTE: SD = standard deviation. FFS is defined as matching a CMS record that identifies Part A and Part B coverage at the time of study enrollment. Not FFS means that the participant did not match to any CMS record or was found to be enrolled in Part A only or in MA. These comparisons are limited to those that were collected by LifePlans (because Medicare data were unavailable for some). Sex was unavailable for those who did not match to a FFS record. We give $p$-values for $t$-tests for comparison of means, and as chi-square tests for comparison of proportions.

\section{Between Those Enrolled Throughout the Intervention Period and Study Dropouts}

Tables 3.3 and 3.4 show baseline comparisons among those matching to FFS Medicare data, specifically comparing those who dropped out prior to the start of the observation window and those who remained in the study until the start of the observation window (in the case of the EG, this means that they completed the fall-prevention intervention). People who dropped out were older and more likely to be in the EG than in the ACG. People who dropped out also had higher baseline Medicare costs than those who remained enrolled in the study.

Table 3.3. Baseline Comparisons, Fee for Service, One Year Pre-Enrollment: Dropped Out Versus Completed Intervention, Patient Characteristics, Group Allocation, Experimental Group and Active Control Group

\begin{tabular}{lcc}
\hline Characteristic & Dropped Out $(\mathbf{N = 4 8 6})$ & Completed Intervention $(\mathbf{N}=\mathbf{3 , 2 8 5})$ \\
\hline Mean age, in years $(p=0.01)$ & 81.1 & 80.6 \\
$\quad$ SD & 4.1 & 3.9 \\
Percentage female $(p=0.74)$ & 58 & \\
Allocated to study arm (excluding ADCG) & & $1,619(49 \%)$ \\
$\quad$ EG $(p<0.001)$ & $366(75 \%)$ & $1,666(51 \%)$ \\
ACG & $120(25 \%)$ & \\
\hline
\end{tabular}

NOTE: Dropout occurred in EG and ACG only. ADCG not included. We give $p$-values for $t$-tests for comparison of means, and chi-square tests for comparison of proportions. 
Table 3.4. Baseline Comparisons, Fee for Service, One Year Pre-Enrollment: Dropped Out Versus Completed Intervention, Baseline Medicare Costs and Emergency Department Visits for Falls, One Year Prior to Enrollment

\begin{tabular}{lccccc}
\hline Characteristic & $\begin{array}{c}\text { Dropped Out } \\
(\boldsymbol{N = 4 8 6})\end{array}$ & $\begin{array}{c}\text { Completed } \\
\text { Intervention } \\
(\boldsymbol{N = 3 , 2 8 5 )}\end{array}$ & Difference & $\begin{array}{c}\mathbf{9 5 \%} \mathrm{Cl} \\
\text { Lower } \\
\text { Bound }\end{array}$ & $\begin{array}{c}\mathbf{9 5 \%} \mathbf{C l} \\
\text { Upper } \\
\text { Bound }\end{array}$ \\
\hline $\begin{array}{l}\text { Medicare costs, in dollars per } \\
\text { person month }\end{array}$ & 937 & 702 & 235 & 98 & 371 \\
$\begin{array}{l}\text { ED visits for fall injuries (per } \\
\begin{array}{l}1,000 \text { person-years) } \\
\hline\end{array}\end{array}$ & 78 & 66 & 12 & -14 & 39 \\
\hline
\end{tabular}

NOTE: Dropout occurred in EG and ACG only. ADCG not included. We give $p$-values for $t$-tests for comparison of means, and chi-square tests for comparison of proportions.

Between Those Randomized to the Experimental Group, the Active Control Group, and the Administrative Control Group

Tables 3.5 and 3.6 provide baseline information by the study arm to which participants were randomized, among those who matched to Medicare FFS records. Patients were, on average, 81 years of age, and a majority (57 to 59 percent) were women, with no statistically significant differences between study arms. Medicare costs in the 12 to 24 months prior to study enrollment were in the range of $\$ 693$ to $\$ 783$ per month and were lower for the EG than for the controls, a difference that is statistically significant if we compare the EG with the ACG and ADCG pooled together as a single control group but in only one in four comparisons between the EG and individual control groups. Baseline ED visits for fall-related injuries were in the range of 58 to 68 per 1,000 person-years and were not statistically significantly different between EG and ACG or ADCG. 
Table 3.5. Fee-for-Service Population, Baseline Comparisons, Experimental Group Versus Active or Administrative Control Group

\begin{tabular}{lccc}
\hline Characteristic & EG $(\boldsymbol{N}=\mathbf{1 , 9 8 5})$ & ACG $(\boldsymbol{N}=\mathbf{1 , 7 8 6})$ & ADCG $(\boldsymbol{N}=\mathbf{1 , 3 6 4})$ \\
\hline Mean age, in years $(p=0.98)$ & 80.7 & 80.7 & 80.6 \\
$\quad(\mathrm{sd})$ & 4.0 & 3.9 & 3.9 \\
Percentage female $(p=0.14)$ & 59 & 57 & 57 \\
Mean costs, per person, per month & & & \\
12-month total person-months & 23,740 & 21,352 & 16,347 \\
12-month average cost, in dollars $(p=0.04)$ & 704 & 765 & 783 \\
$\quad$ SD & 2,679 & 2,852 & 2,885 \\
12 months, mean difference, in dollars, EG - control & N/A & -61 & -80 \\
$\quad$ N5\% Cl & N/A & -136 to 14 & -163 to 4 \\
24-month total person-months & 39,746 & 38,486 & 30,464 \\
24-month average cost, in dollars $(p=0.03)$ & 693 & 762 & 746 \\
$\quad$ SD & 2,592 & 2,941 & 2,972 \\
24 months, mean difference, in dollars, EG - control & N/A & -69 & -54 \\
$\quad$ 95\% Cl & N/A & -133 to -4 & -123 to 16 \\
\hline
\end{tabular}

NOTE: N/A = not applicable. $p$-values test the equality of means (or, for sex, proportions), comparing EG with ACG and ADCG pooled together as a single control group.

Table 3.6. Fee-for-Service Population, Baseline Comparisons, Experimental Group Versus Active or Administrative Control Group: Number of Emergency Department Visits for Fall-Related Injuries, Falls per 1,000 Person-Years

\begin{tabular}{lccc}
\hline Characteristic & EG $(\boldsymbol{N}=\mathbf{1 , 9 8 5})$ & ACG $(\boldsymbol{N}=\mathbf{1 , 7 8 6})$ & ADCG $(\boldsymbol{N}=\mathbf{1 , 3 6 4})$ \\
\hline 12-month total person-months & 23,740 & 21,352 & 16,347 \\
Fall rate, averaged over 12 months $(p=0.90)$ & 66.4 & 68.0 & 66.5 \\
Fall rate, 12-month difference, EG - control & $\mathrm{N} / \mathrm{A}$ & -1.6 & -0.1 \\
\multicolumn{1}{c}{ 95\% Cl } & $\mathrm{N} / \mathrm{A}$ & -18.3 to 15.1 & -17.8 to 17.7 \\
24-month total person-months & 39,746 & 38,486 & 30,464 \\
Fall rate, averaged over 24 months $(p=0.83)$ & 60.9 & 61.0 & 58.0 \\
Fall rate, 24-month difference, EG - control & $\mathrm{N} / \mathrm{A}$ & 0.1 & -2.9 \\
\multicolumn{1}{c}{ 95\% Cl } & & -12.3 to 12.5 & -15.5 to 9.8 \\
\hline
\end{tabular}

NOTE: $p$-values test the equality of means, comparing EG with ACG and ADCG pooled together as a single control group.

\section{Self-Reported Baseline Information in the Experimental Group Versus the Active Control Group}

Baseline characteristics determined during interviews as part of the study protocol yielded additional information for those who remained enrolled at the point at which LifePlans collected these data. For the ACG, people who provided information for this data collection defined the as- 
treated population. For the EG, some who gave this information still dropped out prior to the start of the observation period for falls. There is no self-reported baseline information on the ADCG because, by definition, no interviews were conducted with this group.

Data in Table 3.7 show that 95 percent of the enrolled were white, at least 75 percent having completed some college, and about 50 percent reporting income above $\$ 50,000$ per year. Overall, the sample was quite healthy, with 86 to 87 percent reporting their health as either excellent or good. Nineteen percent reported a fall or fainting episode in the past six months, and only 3 to 4 percent required caregiver assistance.

Table 3.7. Population Characteristics, Baseline Survey: Experimental Group Versus Active Control Group, Fee for Service and Others

\begin{tabular}{|c|c|c|c|}
\hline Characteristic & $\begin{array}{l}\text { EG (Mean or \%); } \\
\qquad N=2,809^{\mathrm{a}}\end{array}$ & $\begin{array}{l}\text { ACG (Mean or } \%) \\
\qquad N=2,451^{\mathrm{a}}\end{array}$ & $\begin{array}{c}p- \\
\text { Value }\end{array}$ \\
\hline$\overline{\text { Age }}$ & 80.8 years & 80.9 years & 0.56 \\
\hline SD & 3.9 years & 3.9 years & \\
\hline Female & $58 \%$ & $58 \%$ & 0.95 \\
\hline Married & $60 \%$ & $60 \%$ & 0.80 \\
\hline Non-Hispanic white & $95 \%$ & $95 \%$ & 0.37 \\
\hline Completed at least some college & $76 \%$ & $75 \%$ & 0.22 \\
\hline Household income $\geq \$ 50,000$ & $52 \%$ & $50 \%$ & 0.12 \\
\hline Overall health excellent or good (versus fair or poor) & $86 \%$ & $87 \%$ & 0.33 \\
\hline At least one ED visit in the past two years & $27 \%$ & $29 \%$ & 0.22 \\
\hline At least one hospital admission in the past two years & $26 \%$ & $28 \%$ & 0.10 \\
\hline Proxy respondents & $2 \%$ & $2 \%$ & 0.48 \\
\hline Receiving caregiver assistance & $3 \%$ & $4 \%$ & 0.13 \\
\hline $\begin{array}{l}\text { One or more episodes of falls or fainting in the past } \\
\text { six months }\end{array}$ & $18 \%$ & $19 \%$ & 0.82 \\
\hline Activity limitation due to fear of falling & $12 \%$ & $13 \%$ & 0.26 \\
\hline Any limitation in instrumental activities of daily living & $16 \%$ & $16 \%$ & 0.69 \\
\hline Any limitation in basic activities of daily living ${ }^{\mathrm{b}}$ & $6 \%$ & $8 \%$ & 0.09 \\
\hline
\end{tabular}

NOTE: This table includes responses from all enrollees who completed the first phone interview after enrollment. For the ACG and ADCG, this is the same as the as-treated population. For the EG, it includes some patients who dropped out at a later stage, prior to completion of the intervention. We give $p$-values for $t$-tests for comparison of means, and chi-square tests for comparison of proportions.

a Denominators differed across items because of different rates of non-response; the number of responses ranged from 2,296 to 2,604 for the EG and from 1,993 to 2,284 for the ACG.

${ }^{\mathrm{b}}$ Basic activities of daily living here include getting in and out of a bed or chair, dressing and undressing oneself, bathing oneself, feeding oneself, toileting, and maintaining continence or caring for personal hygiene after incontinence occurs. Instrumental activities of daily living include taking one's medications, using the telephone, managing one's finances, doing one's housework, shopping for groceries, transporting oneself, and preparing one's meals. 
In this chapter, we present results, organized in the following way: First, using LifePlans data from quarterly telephone follow-up interviews, we performed an analysis similar to that reported in Cohen et al., 2015, comparing self-reported falls in the EG and the ACG, and we demonstrate that the published result holds in the subset of patients identified as Medicare FFS beneficiaries (i.e., our study population). Next, we compare claims-based estimates of the number of ED visits for fall-related injuries (among FFS beneficiaries) between EG and ACG and between EG and ADCG. Third, we compare unadjusted Medicare costs (overall and for injury-related costs) between EG and each of the other two groups, showing graphically how costs compare in the months before and after study enrollment.

\section{Self-Reported Fall Outcomes, As-Treated Population Only}

During quarterly follow-up calls with patients in the EG and ACG, LifePlans collected data on self-reported falls. Table 4.1 summarizes our comparison of self-reported falls between groups.

Table 4.1. Self-Reported Falls Among Those Who Completed Four Quarters of Follow-Up: As Treated

\begin{tabular}{|c|c|c|c|c|c|c|c|}
\hline Participant & $\begin{array}{c}N \\
\text { People }\end{array}$ & $\begin{array}{c}N \\
\text { Falls }\end{array}$ & $\begin{array}{l}\text { Person- } \\
\text { Years }\end{array}$ & $\begin{array}{c}\text { Falls per } \\
\text { 1,000 Person- } \\
\text { Years }\end{array}$ & $\begin{array}{c}\text { Incidence } \\
\text { Rate Ratio } \\
\text { (EG versus } \\
x \text { ) }\end{array}$ & $\begin{array}{l}95 \% \mathrm{Cl} \\
\text { Lower } \\
\text { Bound }\end{array}$ & $\begin{array}{l}95 \% \mathrm{Cl} \\
\text { Upper } \\
\text { Bound }\end{array}$ \\
\hline \multicolumn{8}{|c|}{ All study participants } \\
\hline EG & 1,737 & 778 & 1,946 & 400 & & & \\
\hline ACG & 1,825 & 1,010 & 2,290 & 441 & 0.91 & 0.82 & 1.00 \\
\hline \multicolumn{8}{|c|}{ Identified as Medicare FFS beneficiaries } \\
\hline EG & 1,252 & 577 & 1,401 & 412 & & & \\
\hline ACG & 1,349 & 791 & 1,697 & 466 & 0.88 & 0.79 & 0.99 \\
\hline \multicolumn{8}{|l|}{ All others } \\
\hline EG & 485 & 201 & 545 & 369 & & & \\
\hline ACG & 476 & 219 & 593 & 370 & 1.00 & 0.82 & 1.21 \\
\hline
\end{tabular}

NOTE: This table compares self-reported falls among those who completed four quarters of follow-up (as treated) and who provided an answer as to whether or not they had had recent falls. Self-reported falls cannot be measured in the ADCG because there were no interviews for this arm of the study. We provide results for the FFS subpopulation so that the outcome of self-reported falls can be compared in the same patient population for which we compare claims-based outcomes. "All others" includes all study participants for whom complete claims were not available, including those who did not match any Medicare enrollment record, those without Medicare Part B coverage, and those enrolled in MA. 
Among all study participants who remained enrolled through four quarters of follow-up, we found the rate of self-reported falls to be lower in the EG than in the ACG. We measured 400 per 1,000 person-years in the EG and 441 in the ACG, yielding an incidence rate ratio of 0.91 (95percent $\mathrm{CI}=0.82$ to 1.00 ) - similar to what was reported in Cohen et al., 2015.

We found a similar result when we considered self-reported falls among only the subset of study participants who matched FFS records (incidence rate ratio $0.88 ; 95$-percent $\mathrm{CI}=0.79$ to $0.99)$.

\section{Rates of Emergency Department Visits for Fall-Related Injuries, Estimated from Claims}

Table 4.2 shows estimates of the number of ED visits for fall-related injuries for each group, together with the incidence rate ratio comparing EG and each of the control groups. In the year following study enrollment (intention to treat), the EG had an average 79 fall-related ED visits per 1,000 person-years, as compared with 77 for the ACG and 70 for the ADCG. In the year following the intervention period (as treated), those in the EG who did not drop out had 82 fallrelated ED visits per 1,000 person-years, as compared with 79 and 69 in the ACG and ADCG, respectively. Two-year averages are also shown. None of the comparisons demonstrated any statistically significant differences between study arms. 
Table 4.2. Emergency Department Visits for Fall-Related Injuries, Incidence Rates, and Ratios

\begin{tabular}{|c|c|c|c|c|c|c|c|}
\hline Characteristic & $\begin{array}{c}N \\
\text { People }\end{array}$ & $\begin{array}{l}\text { Person- } \\
\text { Years }\end{array}$ & $\begin{array}{l}N \text { ED Visits } \\
\text { for Fall } \\
\text { Injuries }\end{array}$ & $\begin{array}{c}\text { Fall Injuries per } \\
1,000 \text { Person- } \\
\text { Years }\end{array}$ & $\begin{array}{c}\text { Incidence Rate } \\
\text { Ratio (EG } \\
\text { Versus } x \text { ) }\end{array}$ & $\begin{array}{l}95 \% \mathrm{Cl} \\
\text { Lower } \\
\text { Bound }\end{array}$ & $\begin{array}{l}95 \% \mathrm{CI} \\
\text { Upper } \\
\text { Bound }\end{array}$ \\
\hline \multicolumn{8}{|l|}{ Up to one year } \\
\hline \multicolumn{8}{|c|}{ Intention to treat } \\
\hline EG & 1,985 & 1,964 & 155 & 78.9 & & & \\
\hline ACG & 1,786 & 1,771 & 137 & 77.4 & 1.02 & 0.81 & 1.29 \\
\hline$A D C G$ & 1,364 & 1,351 & 95 & 70.3 & 1.12 & 0.86 & 1.46 \\
\hline \multicolumn{8}{|l|}{ As treated } \\
\hline$E G$ & 1,608 & 1,594 & 130 & 81.6 & & & \\
\hline ACG & 1,665 & 1,651 & 131 & 79.3 & 1.03 & 0.80 & 1.32 \\
\hline$A D C G$ & 1,364 & 1,350 & 93 & 68.9 & 1.18 & 0.90 & 1.56 \\
\hline \multicolumn{8}{|l|}{ Up to two years } \\
\hline \multicolumn{8}{|c|}{ Intention to treat } \\
\hline EG & 1,669 & 3,234 & 266 & 82.3 & & & \\
\hline$A C G$ & 1,618 & 3,147 & 291 & 92.5 & 0.89 & 0.75 & 1.05 \\
\hline ADCG & 1,275 & 2,474 & 190 & 76.8 & 1.07 & 0.89 & 1.30 \\
\hline \multicolumn{8}{|l|}{ As treated } \\
\hline$E G$ & 1,283 & 2,494 & 221 & 88.6 & & & \\
\hline ACG & 1,490 & 2,900 & 272 & 93.8 & 0.94 & 0.79 & 1.13 \\
\hline ADCG & 1,275 & 2,470 & 189 & 76.5 & 1.16 & 0.95 & 1.41 \\
\hline
\end{tabular}

NOTE: We derive the number of ED falls by measuring the number of ED visits with injury diagnoses and then applying a model (as described) to assign a probability of a fall.

\section{Unadjusted Medicare Cost Outcomes}

\section{Total Monthly Health Care Costs, per Person}

Figures 4.1 through 4.4 illustrate mean monthly spending in the year preceding and the year following study enrollment, allowing a visual comparison of unadjusted pre-enrollment and postenrollment costs for the EG, ACG, and ADCG. Figures 4.1 and 4.2 represent the intention-totreat study population; Figures 4.3 and 4.4 represent the as-treated population (the subset of those patients who did not drop out prior to completion of the intervention period). Together, the figures illustrate that average costs prior to enrollment tended to be lower for the EG than for the comparison groups and that, if the EG line were shifted upward to match baseline costs, then, for the months after enrollment, costs would appear similar for the EG and controls. 
Figure 4.1. Monthly Costs, One Year Preceding and Following Enrollment: Intention to Treat

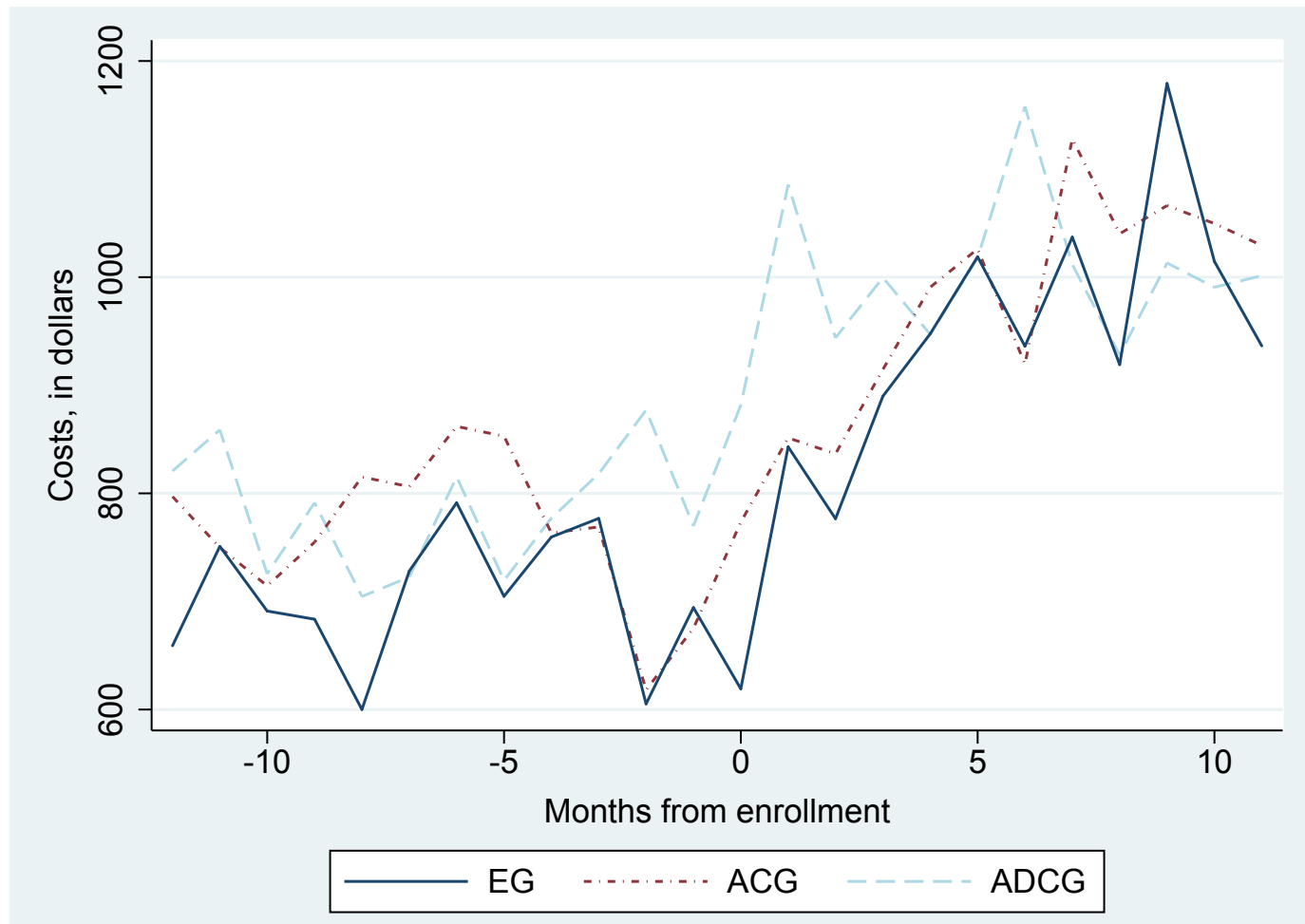

NOTE: Negative values on the $x$-axis (to the left of 0 ) represent baseline costs, prior to enrollment. To allow better visualization of differences, we restrict the $y$-axis to the range of observed values. 
Figure 4.2. Monthly Costs, Two Years Preceding and Following Enrollment: Intention to Treat

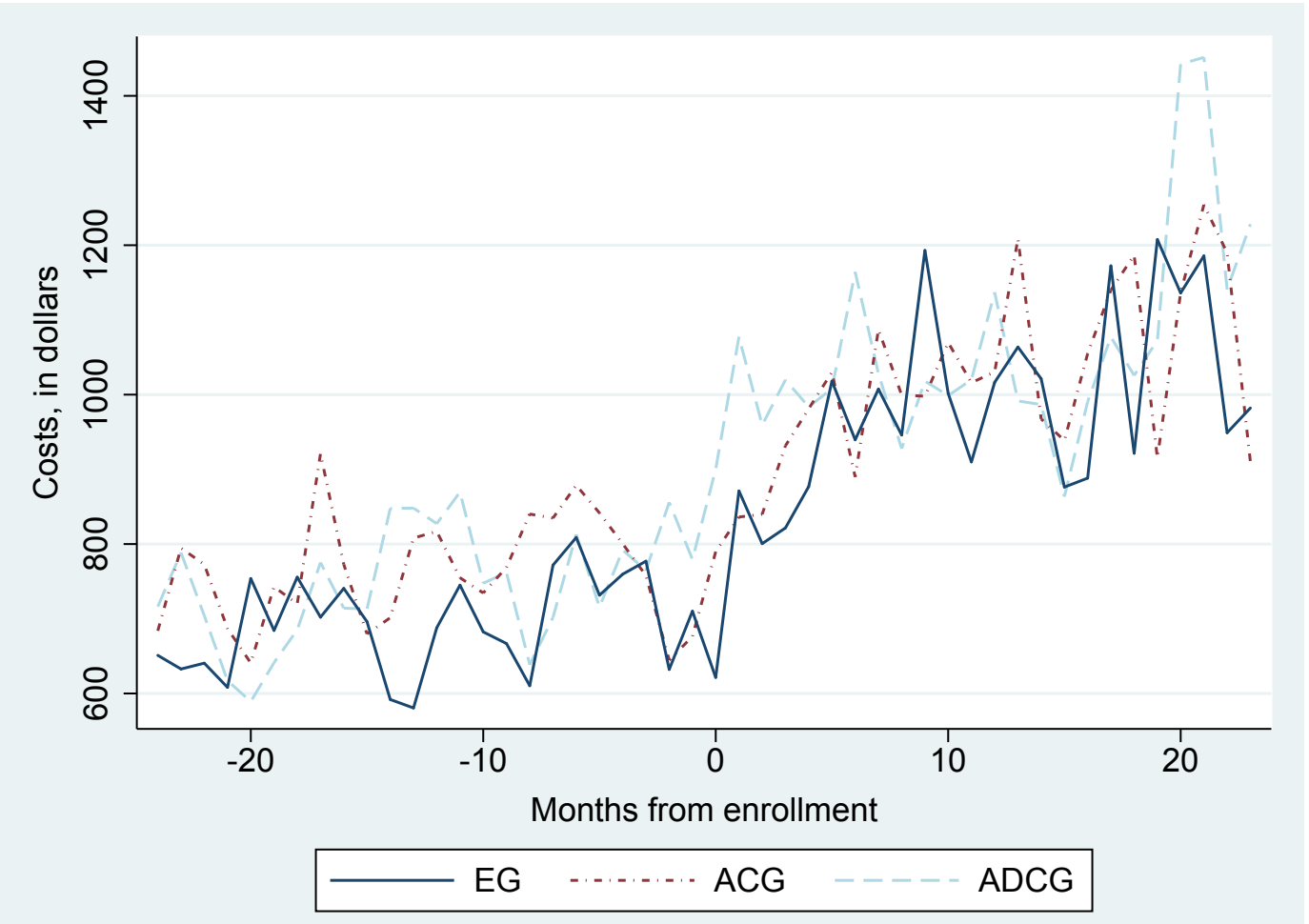

NOTE: Negative values on the $x$-axis (to the left of 0 ) represent baseline costs, prior to enrollment. To allow better visualization of differences, we restrict the $y$-axis to the range of observed values. 
Figure 4.3. Monthly Costs, One Year Preceding and Following Enrollment: As Treated

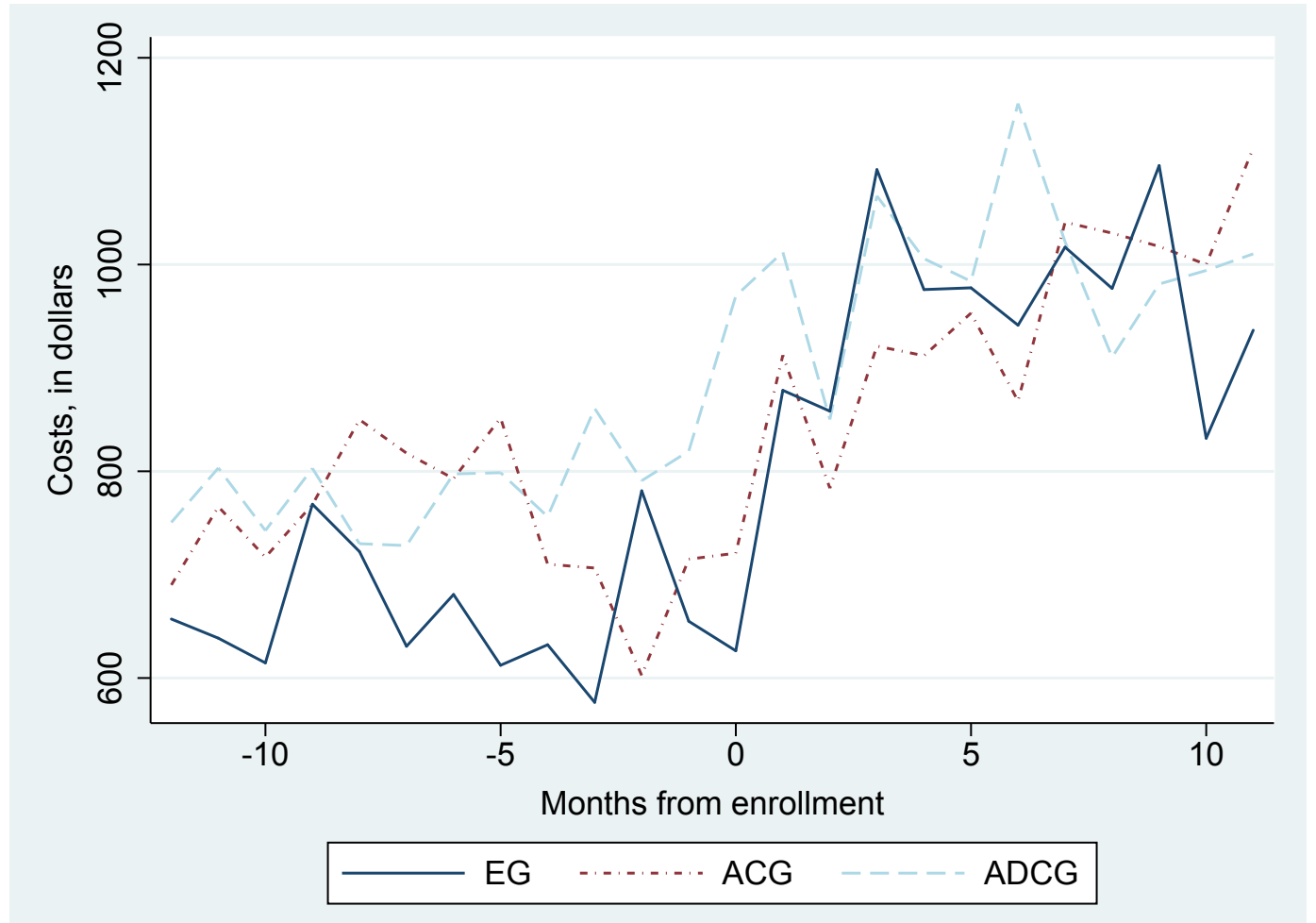

NOTE: Negative values on the $x$-axis (to the left of 0 ) represent baseline costs, prior to the end of the intervention period. To allow better visualization of differences, we restrict the $y$-axis to the range of observed values. 
Figure 4.4. Monthly Costs, Two Years Preceding and Following Enrollment: As Treated

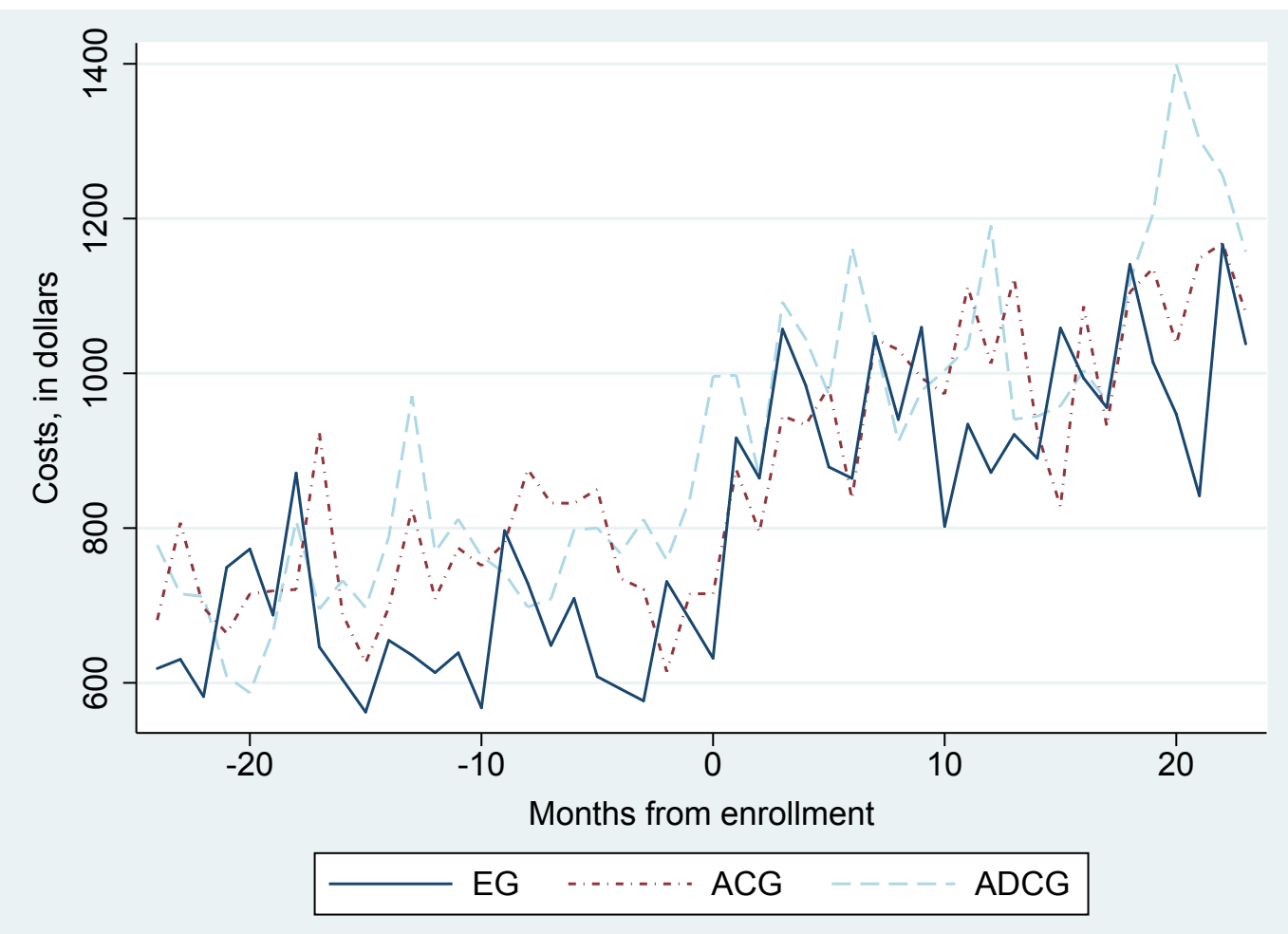

NOTE: Negative values on the $x$-axis (to the left of 0 ) represent baseline costs, prior to the end of the intervention period. To allow better visualization of differences, we restrict the $y$-axis to the range of observed values.

Table 4.3 can be seen as the analytic equivalent of the right side of Figures 4.1 through 4.4, showing the unadjusted average monthly costs for EG, ACG, and ADCG in the one and two years after enrollment. Cost outcome differences between the EG and controls reached statistical significance for only one of the eight comparisons (mean difference, EG versus ADCG at two years, $-\$ 112$; 95-percent $C I=-\$ 217$ to $-\$ 8$ ). Point estimates for mean differences between the EG and either ACG or ADCG were similar in magnitude to the baseline cost differences shown in Tables 3.5 and 3.6, suggesting that outcome differences were consistent with baseline differences. 
Table 4.3. Unadjusted Medicare Cost Outcomes, per Person, per Month, by Group

\begin{tabular}{|c|c|c|c|c|c|c|c|}
\hline Characteristic & $\begin{array}{c}N \\
\text { People }\end{array}$ & $\begin{array}{l}\text { Person- } \\
\text { Months }\end{array}$ & $\begin{array}{l}\text { Mean Costs, } \\
\text { per Person, } \\
\text { per Month, in } \\
\text { Dollars }\end{array}$ & $\begin{array}{l}\text { Monthly } \\
\text { Costs, in } \\
\text { Dollars, SD }\end{array}$ & $\begin{array}{c}\text { Mean } \\
\text { Difference, in } \\
\text { Dollars (EG } \\
\text { Versus } x \text { ) }\end{array}$ & $\begin{array}{l}95 \% \mathrm{CI} \\
\text { Lower } \\
\text { Bound, in } \\
\text { Dollars }\end{array}$ & $\begin{array}{c}95 \% \mathrm{Cl} \\
\text { Upper } \\
\text { Bound, in } \\
\text { Dollars }\end{array}$ \\
\hline \multicolumn{8}{|l|}{ Up to one year } \\
\hline \multicolumn{8}{|c|}{ Intention to treat } \\
\hline EG & 1,985 & 23,567 & 926 & 3,650 & & & \\
\hline ACG & 1,786 & 21,251 & 968 & 3,775 & -43 & -146 & 61 \\
\hline$A D C G$ & 1,364 & 16,207 & 998 & 3,872 & -73 & -188 & 43 \\
\hline \multicolumn{8}{|l|}{ As treated } \\
\hline EG & 1,608 & 19,128 & 934 & 3,669 & & & \\
\hline ACG & 1,665 & 19,813 & 939 & 3,787 & -5 & -116 & 106 \\
\hline$A D C G$ & 1,364 & 16,194 & 997 & 3,873 & -63 & -185 & 58 \\
\hline \multicolumn{8}{|l|}{ Up to two years } \\
\hline \multicolumn{8}{|c|}{ Intention to treat } \\
\hline EG & 1,669 & 38,808 & 978 & 3,804 & & & \\
\hline ACG & 1,618 & 37,766 & 1,021 & 3,814 & -43 & -130 & 44 \\
\hline$A D C G$ & 1,275 & 29,686 & 1,044 & 3,990 & -66 & -162 & 29 \\
\hline \multicolumn{8}{|l|}{ As treated } \\
\hline EG & 1,283 & 29,927 & 950 & 3,529 & & & \\
\hline ACG & 1,490 & 34,799 & 991 & 3,770 & -41 & -138 & 56 \\
\hline$A D C G$ & 1,275 & 29,640 & 1,062 & 4,063 & -112 & -217 & -8 \\
\hline
\end{tabular}

NOTE: This table shows the average monthly costs for all Medicare services in aggregate, starting from date of study enrollment (intention to treat) or completion of the assigned intervention period (as treated). Results are averaged across all months within the one- or two-year time frames in which study participants remained alive and enrolled in Medicare FFS. Because of data limitations, we exclude from the analyses of two-year averages any patients enrolled after October 1, 2012.

Injury-Related Monthly Health Care Costs, per Person

Table 4.4 is analogous to Table 4.3 except that it compares unadjusted injury-related costs (aggregated costs for claims for which there was an injury diagnosis) - a subset of total costs. Injury-related costs were not significantly lower for the EG in any of the comparisons. 
Table 4.4. Unadjusted Injury-Related Medicare Cost Outcomes, per Person, per Month, by Group

\begin{tabular}{|c|c|c|c|c|c|c|c|}
\hline Characteristic & $\begin{array}{c}N \\
\text { People }\end{array}$ & $\begin{array}{l}\text { Person- } \\
\text { Months }\end{array}$ & $\begin{array}{l}\text { Mean Monthly } \\
\text { Costs, per } \\
\text { Person, per } \\
\text { Month, in } \\
\text { Dollars }\end{array}$ & $\begin{array}{c}\text { Monthly } \\
\text { Costs, in } \\
\text { Dollars, SD }\end{array}$ & $\begin{array}{c}\text { Mean } \\
\text { Difference, in } \\
\text { Dollars (EG } \\
\text { Versus } x \text { ) }\end{array}$ & $\begin{array}{l}95 \% \mathrm{Cl} \\
\text { Lower } \\
\text { Bound, in } \\
\text { Dollars }\end{array}$ & $\begin{array}{c}95 \% \mathrm{Cl} \\
\text { Upper } \\
\text { Bound, in } \\
\text { Dollars }\end{array}$ \\
\hline \multicolumn{8}{|l|}{ Up to one year } \\
\hline \multicolumn{8}{|c|}{ Intention to treat } \\
\hline EG & 1,985 & 23,567 & 77 & 1,292 & & & \\
\hline ACG & 1,786 & 21,251 & 60 & 1,065 & 17 & -10 & 44 \\
\hline ADCG & 1,364 & 16,207 & 49 & 743 & 28 & 4 & 52 \\
\hline \multicolumn{8}{|l|}{ As treated } \\
\hline EG & 1,608 & 19,128 & 73 & 1,223 & & & \\
\hline ACG & 1,665 & 19,813 & 56 & 1,009 & 16 & -13 & 45 \\
\hline$A D C G$ & 1,364 & 16,194 & 46 & 666 & 27 & 2 & 51 \\
\hline \multicolumn{8}{|l|}{ Up to two years } \\
\hline \multicolumn{8}{|c|}{ Intention to treat } \\
\hline EG & 1,669 & 38,808 & 70 & 1,187 & & & \\
\hline ACG & 1,618 & 37,766 & 64 & 984 & 6 & -12 & 25 \\
\hline ADCG & 1,275 & 29,686 & 66 & 1,004 & 4 & -17 & 25 \\
\hline \multicolumn{8}{|l|}{ As treated } \\
\hline EG & 1,283 & 29,927 & 69 & 1,113 & & & \\
\hline ACG & 1,490 & 34,799 & 62 & 969 & 7 & -13 & 27 \\
\hline$A D C G$ & 1,275 & 29,640 & 65 & 975 & 4 & -17 & 26 \\
\hline
\end{tabular}

NOTE: This table shows the average monthly costs for all injury-related Medicare services in aggregate, starting from date of study enrollment (intention to treat) or completion of the assigned intervention period (as treated). Results are averaged across all months within the one- or two-year time frames in which study participants remained alive and enrolled in Medicare FFS. Because of data limitations, we exclude from analyses of two-year averages any patients enrolled after October 1, 2012.

\section{Adjusted Outcomes: Average Treatment Effects}

Tables 4.5, 4.6, and 4.7 show results of difference-in-differences regressions estimating the intervention's average effect on each of three outcomes, after adjusting for patient-level differences (age, sex, baseline Medicare costs), and factors related to the timing of each observation: the incidence of fall-related ED visits (Table 4.5), total monthly Medicare costs (Table 4.6), and the subset of total costs that are associated with an injury diagnosis (Table 4.7). The four columns in each table represent four complete sets of regression coefficients for comparisons between the EG and ACG and between the EG and ADCG across one- and twoyear time frames. 
The first row of each of these tables (4.5 through 4.7) provides the result of interest - the average treatment effect. We did not find any case in which the estimates of the intervention's effect on costs differed significantly from 0.

For the pre-specified primary analysis, EG versus ACG, intention to treat, at one year from the date of enrollment, the intervention was associated with a 4-percent increase in the rate of fall-related ED visits (incidence rate ratio, 1.04 [95-percent $\mathrm{CI}=0.74$ to 1.43]) and an \$18-permonth increase [95-percent $\mathrm{CI}=-94$ to 130] in total costs. The point estimate for the effect on injury-related costs was coincidentally the same as for total costs, an \$18-per-month increase, but CIs were narrower [95-percent $\mathrm{CI}=-12$ to 48 ].

Table 4.5. The Intervention's Estimated Effect on Fall-Related Emergency Department Visits

\begin{tabular}{|c|c|c|c|c|}
\hline $\begin{array}{l}\text { Outcome: Fall- } \\
\text { Related ED Visits }\end{array}$ & $\begin{array}{c}\text { Control: ACG } 1 \text { Year } \\
\text { (7,542 observations; } \\
3,771 \text { people) }\end{array}$ & $\begin{array}{c}\text { Control: ACG } \\
2 \text { Years } \\
\text { (6,574 observations; } \\
3,287 \text { people) }\end{array}$ & $\begin{array}{c}\text { Control: ADCG } \\
1 \text { Year } \\
\text { (6,698 observations; } \\
\text { 3,349 people) }\end{array}$ & $\begin{array}{c}\text { Control: ADCG } \\
2 \text { Years } \\
\text { (5,888 observations; } \\
2,944 \text { people) }\end{array}$ \\
\hline Treatment effect & 1.04 & 0.89 & 1.12 & 1.02 \\
\hline $95 \% \mathrm{Cl}$ & 0.76 to 1.43 & 0.70 to 1.14 & 0.79 to 1.60 & 0.77 to 1.35 \\
\hline Post-intervention period & 1.13 & 1.52 & 1.05 & 1.32 \\
\hline SE & 0.13 & 0.13 & 0.15 & 0.14 \\
\hline EG & 0.96 & 0.99 & 0.95 & 1.03 \\
\hline SE & 0.12 & 0.10 & 0.13 & 0.11 \\
\hline Age & 1.08 & 1.07 & 1.07 & 1.07 \\
\hline SE & 0.01 & 0.01 & 0.01 & 0.01 \\
\hline Female & 1.37 & 1.38 & 1.55 & 1.45 \\
\hline SE & 0.13 & 0.11 & 0.16 & 0.12 \\
\hline Calendar year & 1.06 & 0.99 & 1.10 & 1.03 \\
\hline SE & 0.04 & 0.04 & 0.04 & 0.04 \\
\hline
\end{tabular}

NOTE: SE = standard error. This table shows exponentiated coefficients and SE (or 95\% Cls) for difference-indifferences models that compare the intervention's effect on total Medicare costs fit in the four populations defined in the column headings (intention-to-treat analysis). We fit the model as a Poisson regression using data aggregated at the person-year level, with SEs adjusted to account for clustering of data within individuals. The four column headings define four overlapping populations, and the exponentiated coefficients are given for each population. The exponentiated coefficients can be interpreted as incidence rate ratios, such that a value greater than 1 indicates that the variable is associated with an increased incidence of the outcome. The coefficient of interest is for an indicator for "treatment group" (first row), which we define as the interaction between the two indicator variables (for the postintervention period and for assignment to the experimental group) whose coefficients are given in the subsequent rows. Other coefficients represent age, in years; whether female; and calendar year of the observation. Incidence rate ratios are independent of the baseline incident rate, so we do not show the regression constant. Results were robust to different specifications (e.g., a linear regression model, or a model fit using monthly data). 
Table 4.6. The Intervention's Estimated Effect on Total Medicare Costs, in Dollars per Month

\begin{tabular}{|c|c|c|c|c|}
\hline $\begin{array}{l}\text { Outcome: } \\
\text { Medicare } \\
\text { Costs }\end{array}$ & $\begin{array}{c}\text { Control: ACG } 1 \text { Year } \\
\text { (89,920 observations; } \\
3,771 \text { people) }\end{array}$ & $\begin{array}{c}\text { Control: ACG } 2 \text { Years } \\
\text { (154,806 observations; } \\
3,287 \text { people })\end{array}$ & $\begin{array}{c}\text { Control: ADCG } 1 \text { Year } \\
\text { (79,861 observations; } \\
3,349 \text { people) }\end{array}$ & $\begin{array}{c}\text { Control: ADCG } \\
2 \text { Years } \\
(138,704 \text { observations; } \\
2,944 \text { people })\end{array}$ \\
\hline $\begin{array}{l}\text { Average } \\
\text { treatment } \\
\text { effect }\end{array}$ & 18 & 28 & 7 & -33 \\
\hline $95 \% \mathrm{Cl}$ & -94 to 130 & -65 to 121 & -118 to 132 & -138 to 72 \\
\hline $\begin{array}{l}\text { Post- } \\
\text { enrollment } \\
\text { period }\end{array}$ & 187 & 226 & 198 & 280 \\
\hline SE & 44 & 44 & 55 & 53 \\
\hline EG & -55 & -66 & -75 & -52 \\
\hline SE & 38 & 33 & 43 & 36 \\
\hline Age & 26 & 23 & 24 & 23 \\
\hline SE & 5 & 4 & 5 & 4 \\
\hline Female & -162 & -177 & -172 & -160 \\
\hline SE & 38 & 35 & 41 & 36 \\
\hline $\begin{array}{l}\text { Calendar } \\
\text { year }\end{array}$ & -8 & -9 & -6 & -5 \\
\hline SE & 12 & 13 & 14 & 14 \\
\hline Constant & 15,481 & 16,616 & 11,479 & 8,879 \\
\hline SD & 24,293 & 25,840 & 27,295 & 28,322 \\
\hline
\end{tabular}

NOTE: This table shows coefficients and SEs (or 95\% Cls) for a difference-in-differences model of the intervention's effect on total Medicare costs fit in the four populations defined in the column headings. Costs are aggregated at the level of the person-month. We fit the model as a linear regression, with SEs adjusted to account for clustering of monthly data within individuals. The four column headings define four overlapping populations, and the coefficients are given for each population. The coefficients can be interpreted as the intervention's average effect on monthly costs (positive values indicate that costs are higher for the intervention group). The coefficient of interest is for an indicator for "treatment group" (first row), which we define as the interaction between the two indicator variables (for the post-intervention period and for assignment to the experimental group) whose coefficients are given in the subsequent rows. Other coefficients represent age, in years; whether female; and calendar year of the observation. 
Table 4.7. The Intervention's Estimated Effect on Medicare Costs for Injury Care, in Dollars per Month

\begin{tabular}{|c|c|c|c|c|}
\hline $\begin{array}{l}\text { Outcome: } \\
\text { Medicare } \\
\text { Costs }\end{array}$ & $\begin{array}{c}\text { Control: ACG } 1 \text { Year } \\
\text { (89,910 observations, } \\
3,771 \text { people) }\end{array}$ & $\begin{array}{c}\text { Control: ACG } 2 \text { Years } \\
\text { (154,806 observations; } \\
3,287 \text { people) }\end{array}$ & $\begin{array}{c}\text { Control: ADCG } 1 \text { Year } \\
\text { (79,861 observations; } \\
3,349 \text { people) }\end{array}$ & $\begin{array}{c}\text { Control: ADCG } \\
2 \text { Years } \\
\begin{array}{c}(138,704 \text { observations; } \\
2,944 \text { people })\end{array}\end{array}$ \\
\hline $\begin{array}{l}\text { Average } \\
\text { treatment } \\
\text { effect }\end{array}$ & 18 & 28 & 7 & -33 \\
\hline $95 \% \mathrm{Cl}$ & -12 to 48 & -15 to 27 & 7 to 66 & -23 to 23 \\
\hline $\begin{array}{l}\text { Post- } \\
\text { enrollment } \\
\text { period }\end{array}$ & 187 & 226 & 198 & 280 \\
\hline SE & 44 & 44 & 55 & 53 \\
\hline EG & -55 & -66 & -75 & -52 \\
\hline SE & 38 & 33 & 43 & 36 \\
\hline Age & 26 & 23 & 24 & 23 \\
\hline SE & 5 & 4 & 5 & 4 \\
\hline Female & -162 & -177 & -172 & -160 \\
\hline SE & 38 & 35 & 41 & 36 \\
\hline $\begin{array}{l}\text { Calendar } \\
\text { year }\end{array}$ & -8 & -9 & -6 & -5 \\
\hline SE & 12 & 13 & 14 & 14 \\
\hline Constant & 15,481 & 16,616 & 11,479 & 8,879 \\
\hline SE & 24,293 & 25,840 & 27,295 & 28,322 \\
\hline
\end{tabular}

NOTE: This table shows coefficients and SEs (or 95\% Cls) for a difference-in-differences model of the intervention's effect on Medicare costs for care directly associated with injury, fit in the four populations defined in the column headings. Costs are aggregated at the level of the person-month. We fit the model as a linear regression, with SEs adjusted to account for clustering of monthly data within individuals. The four column headings define four overlapping populations, and the coefficients are given for each population. The coefficient of interest is for an indicator for "treatment group" (first row), which we define as the interaction between the two indicator variables (for the post-intervention period and for assignment to the experimental group) whose coefficients are given in the subsequent rows. Other coefficients represent age, in years; whether female; and calendar year of the observation.

\section{Mortality}

Mortality rates were approximately 2 percent at one year and 4 percent at two years (Tables 4.8 and 4.9). There were no significant mortality differences between EG and ACG or between EG and ADCG. 
Table 4.8. One- and Two-Year Mortality: Percentage of the Population Matched to Medicare Record, Including Medicare Advantage

\begin{tabular}{lccc}
\hline Time Frame & EG $(\boldsymbol{N}=\mathbf{2 , 7 1 9})$ & ACG $(\boldsymbol{N}=\mathbf{2 , 3 7 1})$ & ADCG $(\boldsymbol{N}=\mathbf{1 , 8 6 2})$ \\
\hline One year $(p=0.70)$ & 1.6 & 1.8 & 1.9 \\
Two years $(p=0.48)$ & 4.2 & 4.8 & 4.8 \\
\hline
\end{tabular}

NOTE: $p$-values are based on Fisher's exact tests for mortality among the three groups.

Table 4.9. One- and Two-Year Mortality, Intention-to-Treat Analysis: Percentage of the Fee-forService Population Only

\begin{tabular}{lccc}
\hline Time Frame & EG $(\boldsymbol{N}=\mathbf{1 , 9 8 5})$ & ACG $(\boldsymbol{N}=\mathbf{1 , 7 8 6})$ & ADCG $(\boldsymbol{N}=\mathbf{1 , 3 6 4})$ \\
\hline One year $(p=0.28)$ & 1.6 & 1.6 & 2.3 \\
Two years $(p=0.51)$ & 4.3 & 4.6 & 5.2
\end{tabular}

NOTE: $p$-values are based on Fisher's exact tests for mortality among the three groups. 


\section{Chapter Five Discussion}

A 2015 report on a randomized controlled trial of an intervention designed to prevent falls in the elderly found that the intervention reduced claims against long-term care insurance and reduced the number of falls that patients reported in follow-up (Cohen et al., 2015). For this study, ASPE asked RAND to measure the intervention's effect on Medicare spending and to use Medicare claims as an objective measure of whether the intervention reduced the frequency of fall-related injuries leading to medical care. ASPE also asked that we consider our findings in the context of those previously published and give an overall assessment of the intervention's effectiveness.

Using data from the quarterly follow-up interviews that LifePlans provided to us, we confirm that the intervention was associated with a modest reduction in the overall rate of falls as reported by patients themselves, although we do so with the caveat that falls can be measured for only those participants who remained enrolled throughout four quarters of follow-up. In Appendix B, we discuss potential confounders to as-treated and unadjusted analyses. We found that, even in this population of over-75-year-olds enrolled in long-term care insurance, who might be expected to be healthier than average for their age, falls were frequent -440 falls per 1,000 person-years of follow-up in the $\mathrm{ACG}$ - on par with what has been reported for the general 75-and-over population.

We developed and validated a method to measure rates of ED visits for fall-related injuries using Medicare claims, discussed in Appendix A. Applying it to Medicare claims for the 72 percent of study participants identified as enrolled in the FFS program, we found rates of fallrelated ED visits to range from 69 to 93 fall injuries per 1,000 person-years across the various subpopulations we examined. These rates, which are consistent with estimates from a previous study (Tinetti et al., 2008), suggest that, in our study population, approximately one in five patient-reported falls led to an ED visit for an injury. We did not find evidence that the fallprevention intervention reduced ED visits for fall injuries, although imprecision of our estimates (incidence rate ratio, 1.04 ; 95 -percent $\mathrm{CI}=0.74$ to 1.43 ) means that a clinically important difference might have gone undetected.

With regard to Medicare spending, for reasons outlined in Appendix B, we believe that our adjusted analysis provides a more credible estimate of the intervention's effect on costs than unadjusted between-group comparisons. We used a difference-in-differences model, which measures the intervention's average effect while controlling for patient-related factors (e.g., baseline health care spending, sex, age) and temporal trends across the population (i.e., health care inflation). After controlling for these factors, we detected no treatment effect. The 95percent CI for our estimate (ranging from \$94 per person per month in cost savings to \$130 per 
person per month in cost increases) suggests that it is unlikely that a large effect on costs went undetected.

One might expect an intervention of this type, which — by design — encouraged contact with the health care system and the use of certain services, to trigger increased spending for some services while saving costs for fall-related injuries. To evaluate this possibility, we measured the intervention's effect on direct injury-related costs, defined as aggregate costs for the subset of all claims (from any care venue) with an associated injury diagnosis. As was true for total Medicare costs, we did not find evidence that the intervention reduced direct injury-related costs either. In one sense, evaluating only injury-related costs improves the precision of our estimate of intervention effects on costs: Whereas the lower bound of our total cost estimate suggested that up to a \$94-per-month cost savings could have gone undetected, the lower bound of the injuryrelated cost estimate suggests that the intervention yielded no more than $\$ 12$ per month in savings. To the extent that any true cost savings would be expected to come primarily through a reduction in spending for the treatment of injuries, this result improves our confidence that extreme person-to-person variation in overall Medicare spending did not obscure a true effect.

We are hopeful that this work will inform future fall interventions and their evaluation. One question raised in hindsight is whether total Medicare spending is a feasible study outcome for a fall-intervention trial. We found that injury-associated claims account for only 6 to 8 percent of all Medicare costs. Even if all injury costs were related to falls and a fall-prevention program eliminated one-third of fall-related injuries, our results suggest that no more than a 3-percent reduction in overall spending could be expected. ${ }^{7}$ Although it is still a large amount in aggregate dollars, the size of a trial powered to detect such a difference might be prohibitively large.

When the goal is to use health care claims as a surrogate for measuring whether or not a fallrelated injury occurred, either direct injury-related costs or the estimated rate of falls might be measures that are more feasible than total costs. In the LifePlans population, we retrospectively estimate that approximately 6,000 patients in each study arm would have been required for 80 percent power to detect a 20-percent difference in fall injuries. The need for such large study populations is simply a reflection of the fact that, although falls are a major source of morbidity in aggregate, the risk of serious injury to someone in an unselected population is relatively low. This fact suggests that interventions and evaluations of interventions either will need to be population-based and relatively non-resource-intensive or will need to target very high-risk populations that have a high likelihood of benefiting from the intervention. Using claims data to identify falls opens the door to both approaches: Claims can be used both to identify high-risk populations and to track the effectiveness of population-based intervention programs.

\footnotetext{
${ }^{7}$ In Appendix C, we use an alternative methodology to arrive at what we believe to be an upper-bound estimate of $\$ 47$ per month in potential cost savings, excluding the cost of the intervention.
} 
In conclusion, we found no measurable effect of the fall-prevention intervention on Medicare costs or on the rate of ED visits for fall-related injuries. Because only some falls result in injury and only some of those injuries come to medical attention, our results are not necessarily inconsistent with the prior work showing that this intervention reduced self-reported falls and long-term care insurance claims (Cohen et al., 2015). Even if fall-prevention programs result in no cost savings to the health care system, they might still represent a wise use of resources if they represent good value for money compared to alternative uses of resources. Fall-prevention programs would then join the many commonly accepted health care interventions in the Medicare population that do not save money but are considered good value for money (Neumann, Rosen, and Weinstein, 2005). More-formal cost-effectiveness analyses that consider not only costs but also improvements in health could be an important step in understanding the value of these interventions. 


\section{Appendix A \\ Model for Identifying Emergency Department Visits for Fall- Related Injuries}

\section{Overview}

One objective of this study was to develop an algorithm for using Medicare claims to identify episodes of contact with the health care system for acute fall-related injuries. After careful consideration, we chose to limit the evaluation to fall-related visits leading to care in hospital EDs, with or without hospitalization. Although patients can seek initial care for fall-related injuries in other venues (e.g., a primary care office visit), evidence suggests that care episodes, particularly for more-serious injuries, usually begin in the ED.

Falls cause most but not all injuries that result in ED visits by patients 75 and older. When a hospital submits a claim that includes one or more ICD-9 codes defining an acute injury, ${ }^{8}$ it can also submit an accompanying external-cause-of-injury code (E-code), which specifies the mechanism of injury (e.g., fall, motor vehicle accident), as well as the manner or intent (e.g., unintentional). Some states require facilities to submit E-codes, and, increasingly, hospitals are using them even when the law does not require them to do so. Because the proportion of injury claims that include an E-code has changed over time and can vary to some degree by state, region, or facility, one cannot accurately estimate the number of ED visits for fall-related injuries in any given population simply by counting visits with E-codes indicating that a fall occurred.

To circumvent this problem, we created a model that uses ICD-9 codes, patient demographics, and previous claims history to estimate the probability that a fall and not some other mechanism precipitated a given injury-related ED visit. We derived the model using 20132014 100-percent Medicare claims files to identify every ED visit by a FFS beneficiary for which an accompanying E-code identified a specific mechanism of injury $(N=3,481,325) .{ }^{9} \mathrm{We}$ tested model fit by comparing the number of observed versus predicted fall events across deciles of risk, and we validated it externally by making these comparisons after applying the model (i.e., out-of-sample predictions) to earlier years of data $(2006-2012, N=6,733,383)$. The area under the receiver operating characteristic curve was 0.83 in the derivation set and 0.84 when we applied the model coefficients to the validation data. Table A.1 describes goodness of fit and

\footnotetext{
${ }^{8}$ We defined injury as anything with an ICD-9 code in any of the following ranges: 800 to 904,910 to 929,940 to 957 , or 959.

${ }^{9}$ One hundred percent here means that the file contains all claims for all Medicare beneficiaries during those years, as opposed to 5-percent claims files, for example, which contain all claims for a 5-percent random selection of individuals.
} 
model discrimination (both in sample and out of sample). Having derived the model in a very large data set and demonstrated excellent out-of-sample calibration, we applied the model to fallprevention trial data to compare fall-related ED visits across randomization groups, before and after study enrollment.

Table A.1. Model Calibration for In-Sample and Out-of-Sample Predictions of Fall Events Among Emergency Department Visits for Injuries: Observed Versus Predicted Probability, by Risk Decile

\begin{tabular}{llcc}
\hline Decile of Risk Observed or Predicted & Derivation Sample $(\boldsymbol{N}=\mathbf{3 , 4 8 1 , 3 2 5})$ & Validation Sample $(\boldsymbol{N}=\mathbf{6 , 7 3 3 , 3 8 3})$ \\
\hline 1 & Observed & 0.24 & 0.23 \\
2 & Predicted & 0.23 & 0.22 \\
& Observed & 0.51 & 0.51 \\
3 & Predicted & 0.51 & 0.5 \\
& Observed & 0.69 & 0.69 \\
4 & Predicted & 0.69 & 0.69 \\
& Observed & 0.8 & 0.8 \\
5 & Predicted & 0.8 & 0.79 \\
& Observed & 0.86 & 0.86 \\
6 & Predicted & 0.86 & 0.85 \\
& Observed & 0.89 & 0.89 \\
7 & Predicted & 0.9 & 0.9 \\
& Observed & 0.92 & 0.92 \\
8 & Predicted & 0.93 & 0.92 \\
& Observed & 0.94 & 0.94 \\
9 & Predicted & 0.94 & 0.94 \\
& Observed & 0.96 & 0.96 \\
& Predicted & 0.96 & 0.96 \\
& Observed & 0.98 & 0.98 \\
& Predicted & 0.97 & 0.97 \\
\hline
\end{tabular}

NOTE: For each decile, the number of observed fall events (top row in each pair) can be compared with the number of predicted events (bottom row in each pair) in the derivation and validation samples. Fall events are expressed as a proportion of visits in each risk decile with an event. The Hosmer-Lemeshow statistic is known to perform poorly in very large samples, so we do not report it.

\section{Description of the Analytic File and Model}

We created an analytic file consisting of one observation for every ED visit by a FFS beneficiary age 75 or older in which one or more injuries was coded as a principal or secondary 
diagnosis. ${ }^{10}$ We mapped each diagnosis to a cell in the Barell Injury Diagnosis Matrix (Barell et al., 2002; see Centers for Disease Control and Prevention, 2009), which organizes ICD-9 Clinical Modification codes into mutually exclusive cells based on the location of injury (rows) and the type of injury (columns). Model development then proceeded in two stages. First, for each cell in the Barell matrix, we determined the proportion of appearances of that diagnosis in the data for which the accompanying E-code indicated a fall versus some other mechanism. These proportions can be interpreted as the pre-test probability that a given injury diagnosis represents a fall, before accounting for each patient's individual characteristics, or considering the effect of multiple injuries diagnosed during the same visit. Table A.2 maps injuries to pre-test probabilities.

${ }^{10}$ We defined an ED visit as any MEDPAR record with nonzero ED charges or any outpatient-file record with Revenue Center Code between 0450 and 0459. See Research Data Assistance Center, 2015. We defined an injury as anything with an ICD-9 code in any of the following ranges: 800 to 904,910 to 929,940 to 957 , or 959 . 
Table A.2. Percentage of Injuries That Are Fall-Related (Versus Caused by a Different Mechanism)

\begin{tabular}{|c|c|c|c|c|c|c|c|c|c|c|c|c|c|}
\hline Injury & Fractures & Dislocation & $\begin{array}{l}\text { Sprains } \\
\text { and } \\
\text { Strains }\end{array}$ & $\begin{array}{c}\text { Internal } \\
\text { Organ }\end{array}$ & $\begin{array}{c}\text { Open } \\
\text { Wounds }\end{array}$ & Amputations & $\begin{array}{c}\text { Blood } \\
\text { Vessels }\end{array}$ & $\begin{array}{l}\text { Superficial } \\
\text { or } \\
\text { Contusion }\end{array}$ & Crushing & Burns & Nerves & Unspecified & $\begin{array}{l}\text { Systemwide } \\
\text { and Late } \\
\text { Effects }\end{array}$ \\
\hline Type 1 TBI & 88.8 & & & 92.6 & & & & & & & 87.5 & & \\
\hline Type 2 TBI & 90.2 & & & 89.6 & & & & & & & & & \\
\hline Type 3 TBI & 93.6 & & & & & & & & & & & & \\
\hline Other head & & & & & 91.5 & & & & & & 77.8 & 93.7 & \\
\hline Face & 94.0 & 30.3 & 65.4 & & 91.0 & & & & & 3.0 & & & \\
\hline Eye & & & & & 86.5 & & & 79.6 & & 3.5 & 76.5 & & \\
\hline Neck & 47.6 & & & & 59.6 & & & & & & 71.1 & & \\
\hline $\begin{array}{l}\text { Head, face, } \\
\text { or neck, } \\
\text { unspecified }\end{array}$ & & & & & & & 74.6 & 93.0 & 78.1 & 2.9 & 70.6 & 90.6 & \\
\hline $\begin{array}{l}\text { Cervical } \\
\text { SCl }\end{array}$ & 80.4 & & & 85.5 & & & & & & & & & \\
\hline $\begin{array}{l}\text { Thoracic or } \\
\text { dorsal SCl }\end{array}$ & 78.2 & & & 80.0 & & & & & & & & & \\
\hline Lumbar SCl & 78.3 & & & 88.0 & & & & & & & & & \\
\hline $\begin{array}{l}\text { Sacrum or } \\
\text { coccyx SCl }\end{array}$ & 84.1 & & & & & & & & & & & & \\
\hline $\begin{array}{l}\text { Spine or } \\
\text { back, } \\
\text { unspecified } \\
\text { SCl }\end{array}$ & 78.6 & & & 84.1 & & & & & & & & & \\
\hline $\begin{array}{l}\text { Cervical } \\
\mathrm{VCl}\end{array}$ & 86.6 & 87.1 & 77.2 & & & & & & & & & & \\
\hline $\begin{array}{l}\text { Thoracic or } \\
\text { dorsal VCl }\end{array}$ & 78.0 & 90.2 & 67.0 & & & & & & & & & & \\
\hline Lumbar VCl & 78.2 & 84.9 & 67.8 & & & & & & & & & & \\
\hline $\begin{array}{l}\text { Sacrum or } \\
\text { coccyx VCl }\end{array}$ & 89.4 & 71.7 & 84.7 & & & & & & & & & & \\
\hline
\end{tabular}




\begin{tabular}{|c|c|c|c|c|c|c|c|c|c|c|c|c|c|}
\hline Injury & Fractures & Dislocation & $\begin{array}{l}\text { Sprains } \\
\text { and } \\
\text { Strains }\end{array}$ & $\begin{array}{c}\text { Internal } \\
\text { Organ }\end{array}$ & $\begin{array}{c}\text { Open } \\
\text { Wounds }\end{array}$ & Amputations & $\begin{array}{l}\text { Blood } \\
\text { Vessels }\end{array}$ & $\begin{array}{c}\text { Superficial } \\
\text { or } \\
\text { Contusion }\end{array}$ & Crushing & Burns & Nerves & Unspecified & $\begin{array}{l}\text { Systemwide } \\
\text { and Late } \\
\text { Effects }\end{array}$ \\
\hline $\begin{array}{l}\text { Spine or } \\
\text { back, } \\
\text { unspecified } \\
\text { VCl }\end{array}$ & 69.2 & 81.3 & & & & & & & & & & & \\
\hline Chest & 83.7 & 76.0 & 57.4 & 71.9 & 54.9 & & 33.9 & 84.8 & & 6.8 & & & \\
\hline Abdomen & & & & 63.1 & 38.4 & & 43.6 & 78.8 & & 4.2 & & & \\
\hline $\begin{array}{l}\text { Pelvis or } \\
\text { urogenital }\end{array}$ & 93.2 & 63.2 & 67.8 & 53.2 & 52.6 & & 57.3 & 73.8 & & & & & \\
\hline Trunk & 79.0 & & & & 66.5 & & & 62.8 & 55.0 & 7.9 & & 85.2 & \\
\hline $\begin{array}{l}\text { Back or } \\
\text { buttock }\end{array}$ & & & 69.7 & & 82.4 & & & 95.1 & 70.6 & 8.9 & & & \\
\hline $\begin{array}{l}\text { Shoulder or } \\
\text { upper arm }\end{array}$ & 93.3 & 88.1 & 73.8 & & 82.3 & & & 90.0 & 61.7 & 6.0 & & 88.0 & \\
\hline $\begin{array}{l}\text { Forearm or } \\
\text { elbow }\end{array}$ & 93.9 & 91.9 & 76.3 & & 77.1 & & & 87.8 & 28.5 & 4.2 & & & \\
\hline $\begin{array}{l}\text { Hand, wrist, } \\
\text { or finger }\end{array}$ & 76.2 & 88.3 & 83.3 & & 40.4 & 3.6 & & 74.9 & 3.6 & 2.4 & & 62.4 & \\
\hline $\begin{array}{l}\text { Other or } \\
\text { unspecified } \\
\text { upper } \\
\text { extremity }\end{array}$ & 79.3 & & & & 80.8 & & 37.6 & 83.4 & 37.9 & 3.5 & 57.9 & 87.4 & \\
\hline Hip & 96.9 & 43.2 & 74.2 & & & & & 96.1 & & & & & \\
\hline $\begin{array}{l}\text { Upper leg } \\
\text { or thigh }\end{array}$ & 90.9 & & & & & & & 84.7 & & 4.8 & & & \\
\hline Knee & 91.4 & 64.3 & 68.4 & & & & & 92.6 & 46.7 & 7.5 & & & \\
\hline $\begin{array}{l}\text { Lower leg } \\
\text { or ankle }\end{array}$ & 79.3 & 76.7 & 68.5 & & & & & 66.6 & 8.8 & 2.7 & & & \\
\hline Foot or toe & 63.3 & 63.2 & 58.8 & & 23.4 & 16.9 & & 49.6 & 4.1 & 2.4 & & & \\
\hline $\begin{array}{l}\text { Other or } \\
\text { unspecified } \\
\text { lower } \\
\text { extremity }\end{array}$ & 68.2 & & 68.9 & & 48.3 & & 42.2 & 78.1 & 27.7 & 5.2 & & 80.4 & \\
\hline
\end{tabular}




\begin{tabular}{|c|c|c|c|c|c|c|c|c|c|c|c|c|c|}
\hline Injury & Fractures & Dislocation & $\begin{array}{l}\text { Sprains } \\
\text { and } \\
\text { Strains }\end{array}$ & $\begin{array}{c}\text { Internal } \\
\text { Organ }\end{array}$ & $\begin{array}{c}\text { Open } \\
\text { Wounds }\end{array}$ & Amputations & $\begin{array}{l}\text { Blood } \\
\text { Vessels }\end{array}$ & $\begin{array}{c}\text { Superficial } \\
\text { or } \\
\text { Contusion }\end{array}$ & Crushing & Burns & Nerves & Unspecified & $\begin{array}{l}\text { Systemwide } \\
\text { and Late } \\
\text { Effects }\end{array}$ \\
\hline $\begin{array}{l}\text { Other or } \\
\text { multiple, not } \\
\text { elsewhere } \\
\text { classified }\end{array}$ & 71.1 & & & & & & 51.5 & & & & 70.1 & & \\
\hline Unspecified & 69.5 & 80.0 & 53.9 & 61.1 & 83.0 & & 56.8 & 87.8 & 34.9 & 3.2 & 53.4 & 89.2 & \\
\hline $\begin{array}{l}\text { Systemwide } \\
\text { and late } \\
\text { effects }\end{array}$ & & & & & & & & & & & & & 19.4 \\
\hline
\end{tabular}


Whereas we created Table A.2 by considering each injury diagnosis as an independent event, the final prediction model considers up to three injuries diagnosed during the visit, along with the patient's age, sex, and ED visits for injuries during the preceding 365 days, to create a probability that a fall caused the injury diagnosed during the visit. We use mappings from Table A.2 as predictors for the final model in the following way: We map up to three injury diagnoses to Table A.2 to generate three pre-test probabilities (p1, p2, and p3). We then create a parallel set of quantile variables (Q1, Q2, and Q3) that contain numbers from 1 to 20, which represent 20 quantiles of the corresponding probability variable. We define the quantiles separately for each pre-test probability (see Tables A.3 through A.7). We set a quantile to 0 if the corresponding diagnosis variable is missing (e.g., Q1 would be missing if the principal diagnosis were not for injury; Q3 would be missing if there were only one or two coded injury diagnoses). Each quantile enters the model as a series of indicator variables, specific to each diagnostic position (Q1, Q2, and Q3), with the base category for comparison of each variable being that the quantile variable had been set to 0 .

Table A.3. Categorization of Probability Mappings from Table A.2 into 20 Quantiles, One for Each Predictor Variable: Principal Diagnosis, 20 Quantiles of Probability

\begin{tabular}{lllc}
\hline Quantile & Low Probability & High Probability & Number in Quantile \\
\hline 1 & 0.000 & 0.386 & 181,483 \\
2 & 0.387 & 0.603 & 191,476 \\
3 & 0.603 & 0.672 & 168,113 \\
4 & 0.673 & 0.742 & 174,702 \\
5 & 0.745 & 0.756 & 198,524 \\
6 & 0.760 & 0.767 & 151,868 \\
7 & 0.769 & 0.804 & 163,571 \\
8 & 0.813 & 0.851 & 225,731 \\
9 & 0.854 & 0.861 & 122,840 \\
10 & 0.865 & 0.885 & 139,330 \\
11 & 0.886 & 0.908 & 306,195 \\
12 & 0.916 & 0.923 & 72,261 \\
13 & 0.923 & 0.928 & 338,175 \\
14 & 0.931 & 0.931 & 10,527 \\
15 & 0.931 & 0.936 & 182,683 \\
16 & 0.936 & 0.945 & 205,410 \\
17 & 0.946 & 0.952 & 127,951 \\
18 & 0.957 & 1.000 & 335,150 \\
\hline
\end{tabular}

NOTE: As described in the text, we translate the probability of each predictor variable into a probability quantile, and each quantile enters the model as a series of indicator variables. The range of probabilities (or sums of probabilities) that defines each quantile is determined from the derivation data set and not recalculated when the model is used in making out-of-sample predictions. 
Table A.4. Categorization of Probability Mappings from Table A.2 into 20 Quantiles, One for Each Predictor Variable: First Additional Injury Diagnosis, 20 Quantiles of Probability

\begin{tabular}{lccc}
\hline Quantile & Low Probability & High Probability & Number in Quantile \\
\hline 1 & 0.000 & 0.538 & 100,399 \\
2 & 0.545 & 0.671 & 96,821 \\
3 & 0.672 & 0.732 & 93,768 \\
4 & 0.742 & 0.763 & 94,323 \\
5 & 0.764 & 0.796 & 97,696 \\
6 & 0.796 & 0.821 & 92,823 \\
7 & 0.821 & 0.850 & 94,096 \\
8 & 0.850 & 0.868 & 108,557 \\
9 & 0.869 & 0.881 & 110,975 \\
10 & 0.882 & 0.898 & 68,778 \\
11 & 0.900 & 0.912 & 129,055 \\
12 & 0.916 & 0.918 & 62,680 \\
13 & 0.919 & 0.928 & 112,022 \\
14 & 0.928 & 0.928 & 192,756 \\
16 & 0.931 & 0.936 & 253,578 \\
18 & 0.936 & 0.940 & 56,236 \\
19 & 0.941 & 0.957 & 68,486 \\
20 & 0.960 & 1.000 & 81,002 \\
\hline
\end{tabular}

NOTE: As described in the text, we translate the probability of each predictor variable into a probability quantile, and each quantile enters the model as a series of indicator variables. The range of probabilities (or sums of probabilities) that defines each quantile is determined from the derivation data set and not recalculated when the model is used in making out-of-sample predictions. 
Table A.5. Categorization of Probability Mappings from Table A.2 into 20 Quantiles, One for Each Predictor Variable: Second Additional Injury Diagnosis, 20 Quantiles of Probability

\begin{tabular}{llcc}
\hline Quantile & Low Probability & High Probability & Number in Quantile \\
\hline 1 & 0.000 & 0.631 & 27,291 \\
2 & 0.632 & 0.732 & 28,941 \\
3 & 0.742 & 0.771 & 34,541 \\
4 & 0.772 & 0.804 & 18,790 \\
5 & 0.813 & 0.839 & 26,800 \\
6 & 0.839 & 0.868 & 27,494 \\
7 & 0.869 & 0.881 & 32,697 \\
8 & 0.882 & 0.906 & 30,266 \\
9 & 0.908 & 0.912 & 19,473 \\
10 & 0.916 & 0.921 & 26,898 \\
11 & 0.923 & 0.928 & 29,933 \\
12 & 0.928 & 0.928 & 79,965 \\
15 & 0.931 & 0.936 & 100,048 \\
18 & 0.936 & 0.940 & 25,637 \\
19 & 0.941 & 0.957 & 16,679 \\
20 & 0.960 & 1.000 & 19,822 \\
\hline
\end{tabular}

NOTE: As described in the text, we translate the probability of each predictor variable into a probability quantile, and each quantile enters the model as a series of indicator variables. The range of probabilities (or sums of probabilities) that defines each quantile is determined from the derivation data set and not recalculated when the model is used in making out-of-sample predictions. 
Table A.6. Categorization of Probability Mappings from Table A.2 into 20 Quantiles, One for Each Predictor Variable: Sum of Current Injury Probabilities, 20 Quantiles

\begin{tabular}{lccc}
\hline Quantile & Low Probability & High Probability & Number in Quantile \\
\hline 1 & 0.000 & 0.452 & 238,666 \\
2 & 0.458 & 0.663 & 186,099 \\
3 & 0.663 & 0.732 & 196,799 \\
4 & 0.732 & 0.764 & 221,590 \\
5 & 0.765 & 0.818 & 193,483 \\
6 & 0.819 & 0.854 & 203,324 \\
7 & 0.855 & 0.888 & 206,508 \\
8 & 0.888 & 0.912 & 238,270 \\
9 & 0.912 & 0.928 & 177,135 \\
10 & 0.928 & 0.931 & 203,804 \\
11 & 0.931 & 0.939 & 236,455 \\
12 & 0.939 & 0.957 & 184,778 \\
13 & 0.957 & 0.972 & 303,025 \\
14 & 0.972 & 1.443 & 101,295 \\
15 & 1.443 & 1.683 & 206,666 \\
16 & 1.683 & 1.797 & 207,033 \\
17 & 1.797 & 1.847 & 230,017 \\
18 & 1.847 & 1.897 & 183,903 \\
19 & 1.897 & 2.588 & 204,958 \\
20 & 2.588 & - & 206,512 \\
\hline
\end{tabular}

NOTE: As described in the text, we translate the probability of each predictor variable into a probability quantile, and each quantile enters the model as a series of indicator variables. The range of probabilities (or sums of probabilities) that defines each quantile is determined from the derivation data set and not recalculated when the model is used in making out-of-sample predictions. 
Table A.7. Categorization of Probability Mappings from Table A.2 into 20 Quantiles, One for Each Predictor Variable: Cumulative Previous Emergency Department Injuries, 20 Quantiles

\begin{tabular}{llll}
\hline Quantile & Low Probability & High Probability & Number in Quantile \\
\hline 1 & 0.000 & 0.452 & 238,666 \\
2 & 0.622 & 0.663 & 186,099 \\
3 & 0.753 & 0.732 & 196,799 \\
4 & 0.792 & 0.764 & 221,590 \\
5 & 0.852 & 0.818 & 193,483 \\
6 & 0.869 & 0.854 & 203,324 \\
7 & 0.909 & 0.888 & 206,508 \\
8 & 0.923 & 0.912 & 238,270 \\
9 & 0.929 & 0.928 & 177,135 \\
10 & 0.931 & 0.931 & 203,804 \\
11 & 0.936 & 0.939 & 236,455 \\
12 & 0.939 & 0.957 & 184,778 \\
13 & 0.951 & 0.972 & 303,025 \\
14 & 0.961 & 1.443 & 101,295 \\
15 & 1.306 & 1.683 & 206,666 \\
16 & 1.695 & 1.797 & 207,033 \\
17 & 1.814 & 1.847 & 230,017 \\
18 & 1.869 & 1.897 & 183,903 \\
19 & 2.323 & 2.588 & 204,958 \\
20 & 2.813 & - & 206,512 \\
\hline
\end{tabular}

Note: As described in the text, we translate the probability of each predictor variable into a probability quantile, and each quantile enters the model as a series of indicator variables. The range of probabilities (or sums of probabilities) that defines each quantile is determined from the derivation data set and not recalculated when the model is used in making out-of-sample predictions.

For example, if a given patient has a toe-crush injury as the principal diagnosis, the corresponding probability from Table A.2 is 4.1 percent (read across the "Foot or toe" row to the "Crushing" column). In Table A.3 (because this is the principal diagnosis), that probability is in the first quantile ( 0.041 being between 0.000 and 0.386 ), which represents 181,483 patients, or 5 percent of the derivation sample. If there are no other coded injuries, Q2 and Q3 are each set to 0 , and diagnoses enter the final regression model for an indicator for Q1_quantile_1 = 1 . Importantly, quantiles are defined by the distribution in the derivation population - their boundaries are not reset when the model is applied to a new population.

This method, although cumbersome to describe, takes full advantage of the very large size of the derivation set to allow the pre-test probabilities to be used as predictors without making distributional assumptions. The use of quantiles of probabilities as predictors is more flexible than using dummy variables for each cell in the barrel matrix, principally because it offers a 
parsimonious way of considering the interaction of multiple injury diagnoses during the same visit.

We also created two additional sets of predictors derived from these proportions: (1) the sum of individual proportions (up to three) associated with the current visit and (2) the sum of the highest single injury-associated proportion for ED visits by the same patient in the preceding 365 days. We entered each of these into the model as a quantile. Tables A.3 through A.7 give the relationship between each proportion or sum and its respective quantile. Table A. 8 describes the full regression results.

Table A.8. Regression Results for Model of Probability of Fall Conditional on Coded Injury Diagnoses and Patient Characteristics

\begin{tabular}{|c|c|c|c|}
\hline Independent Variable & Odds Ratio & 95\% CI Lower Bound & $\begin{array}{l}95 \% \text { Cl Upper } \\
\text { Bound }\end{array}$ \\
\hline \multicolumn{4}{|c|}{$\begin{array}{l}\text { Principal diagnosis, quantile of associated } \\
\text { proportion }\end{array}$} \\
\hline 1 & 0.464 & 0.453 & 0.474 \\
\hline 2 & 0.796 & 0.781 & 0.812 \\
\hline 3 & 1.062 & 1.042 & 1.082 \\
\hline 4 & 1.095 & 1.072 & 1.118 \\
\hline 5 & 1.502 & 1.475 & 1.530 \\
\hline 6 & 0.943 & 0.921 & 0.965 \\
\hline 7 & 0.914 & 0.896 & 0.932 \\
\hline 8 & 0.672 & 0.660 & 0.684 \\
\hline 9 & 0.729 & 0.707 & 0.751 \\
\hline 10 & 0.961 & 0.941 & 0.981 \\
\hline 11 & 0.976 & 0.957 & 0.995 \\
\hline 12 & 1.003 & 0.958 & 1.050 \\
\hline 13 & 1.355 & 1.328 & 1.382 \\
\hline 15 & 1.736 & 1.675 & 1.799 \\
\hline 16 & 2.223 & 2.176 & 2.272 \\
\hline 17 & 1.680 & 1.622 & 1.739 \\
\hline 18 & 2.862 & 2.732 & 2.999 \\
\hline Non-injury diagnosis & (omitted) & & \\
\hline \multicolumn{4}{|c|}{$\begin{array}{l}\text { First additional injury diagnosis, quantile of } \\
\text { associated proportion }\end{array}$} \\
\hline 1 & 0.389 & 0.380 & 0.397 \\
\hline 2 & 0.607 & 0.593 & 0.621 \\
\hline 3 & 0.680 & 0.664 & 0.697 \\
\hline 4 & 0.988 & 0.966 & 1.011 \\
\hline 5 & 0.682 & 0.666 & 0.698 \\
\hline
\end{tabular}




\begin{tabular}{|c|c|c|c|}
\hline Independent Variable & Odds Ratio & 95\% CI Lower Bound & $\begin{array}{l}95 \% \text { Cl Upper } \\
\text { Bound }\end{array}$ \\
\hline 6 & 0.663 & 0.648 & 0.678 \\
\hline 7 & 0.644 & 0.629 & 0.659 \\
\hline 8 & 0.685 & 0.670 & 0.701 \\
\hline 9 & 0.859 & 0.840 & 0.879 \\
\hline 10 & 0.700 & 0.674 & 0.728 \\
\hline 11 & 1.329 & 1.296 & 1.362 \\
\hline 12 & 0.944 & 0.907 & 0.983 \\
\hline 13 & 0.578 & 0.559 & 0.597 \\
\hline 14 & 1.444 & 1.413 & 1.476 \\
\hline 16 & 0.814 & 0.783 & 0.845 \\
\hline 18 & 0.784 & 0.732 & 0.840 \\
\hline 19 & 1.217 & 1.170 & 1.267 \\
\hline 20 & 1.724 & 1.659 & 1.792 \\
\hline \multicolumn{4}{|c|}{$\begin{array}{l}\text { Second additional injury diagnosis, } \\
\text { quantile of associated proportion }\end{array}$} \\
\hline 1 & 0.434 & 0.419 & 0.450 \\
\hline 2 & 0.598 & 0.577 & 0.620 \\
\hline 3 & 0.989 & 0.953 & 1.027 \\
\hline 4 & 0.587 & 0.559 & 0.616 \\
\hline 5 & 0.724 & 0.694 & 0.755 \\
\hline 6 & 0.614 & 0.590 & 0.639 \\
\hline 7 & 1.067 & 1.024 & 1.112 \\
\hline 8 & 0.914 & 0.875 & 0.954 \\
\hline 9 & 1.833 & 1.722 & 1.951 \\
\hline 10 & 0.805 & 0.766 & 0.845 \\
\hline 11 & 0.418 & 0.394 & 0.442 \\
\hline 12 & 1.831 & 1.768 & 1.896 \\
\hline 15 & 0.524 & 0.492 & 0.558 \\
\hline 18 & 0.617 & 0.487 & 0.783 \\
\hline 19 & 1.675 & 1.522 & 1.844 \\
\hline 20 & 1.657 & 1.551 & 1.769 \\
\hline \multicolumn{4}{|c|}{$\begin{array}{l}\text { Quantiles of total probability, or the sum of } \\
\text { probabilities associated with up to three } \\
\text { injury diagnoses }\end{array}$} \\
\hline 1 & 0.074 & 0.072 & 0.076 \\
\hline 2 & 0.171 & 0.167 & 0.174 \\
\hline 3 & 0.184 & 0.181 & 0.188 \\
\hline 4 & 0.249 & 0.245 & 0.254 \\
\hline 5 & 0.345 & 0.338 & 0.352 \\
\hline
\end{tabular}




\begin{tabular}{|c|c|c|c|}
\hline Independent Variable & Odds Ratio & 95\% CI Lower Bound & $\begin{array}{c}95 \% \text { CI Upper } \\
\text { Bound }\end{array}$ \\
\hline 6 & 0.792 & 0.778 & 0.807 \\
\hline 7 & 0.874 & 0.857 & 0.890 \\
\hline 9 & 1.656 & 1.608 & 1.705 \\
\hline 10 & 1.054 & 1.029 & 1.080 \\
\hline 11 & 1.883 & 1.841 & 1.925 \\
\hline 12 & 1.852 & 1.805 & 1.900 \\
\hline 13 & 1.471 & 1.400 & 1.546 \\
\hline 14 & 0.640 & 0.624 & 0.656 \\
\hline 15 & 1.232 & 1.208 & 1.257 \\
\hline 16 & 1.981 & 1.939 & 2.023 \\
\hline 17 & 2.064 & 2.022 & 2.108 \\
\hline 18 & 2.088 & 2.031 & 2.146 \\
\hline 19 & 1.652 & 1.612 & 1.694 \\
\hline 20 & 1.992 & 1.941 & 2.044 \\
\hline \multicolumn{4}{|c|}{$\begin{array}{l}\text { Cumulative sum of probabilities associated } \\
\text { with the principal diagnosis for previous } \\
\text { ED visits for injury within the previous year }\end{array}$} \\
\hline 1 & 0.800 & 0.781 & 0.820 \\
\hline 2 & 0.932 & 0.909 & 0.955 \\
\hline 3 & 0.964 & 0.935 & 0.994 \\
\hline 4 & 1.106 & 1.072 & 1.140 \\
\hline 5 & 1.300 & 1.261 & 1.340 \\
\hline 6 & 1.244 & 1.210 & 1.278 \\
\hline 7 & 1.500 & 1.440 & 1.561 \\
\hline 8 & 1.470 & 1.437 & 1.503 \\
\hline 9 & 1.259 & 1.082 & 1.463 \\
\hline 10 & 1.147 & 1.074 & 1.224 \\
\hline 11 & 0.650 & 0.379 & 1.115 \\
\hline 12 & 1.246 & 1.202 & 1.290 \\
\hline 13 & 1.645 & 1.568 & 1.725 \\
\hline 14 & 1.248 & 1.211 & 1.287 \\
\hline 15 & 1.190 & 1.158 & 1.223 \\
\hline 16 & 1.552 & 1.506 & 1.599 \\
\hline 17 & 1.889 & 1.826 & 1.954 \\
\hline 18 & 1.663 & 1.610 & 1.718 \\
\hline 19 & 1.856 & 1.797 & 1.917 \\
\hline 20 & 2.049 & 1.982 & 2.118 \\
\hline \multicolumn{4}{|l|}{ Patient characteristics } \\
\hline Age & 1.132 & 1.119 & 1.144 \\
\hline
\end{tabular}


Independent Variable

Age ${ }^{\wedge} 2$

Female

Admitted to hospital

Syncope diagnosis

Constant

\section{Odds Ratio}

1.000

1.355

1.504

3.097

0.003
95\% Cl Lower Bound

1.000

1.346

1.488

2.981

0.002
95\% Cl Upper Bound

1.000

1.364

1.521

3.218

0.005

NOTE: This table shows the exponentiated coefficients and $95 \%$ Cls for a model that predicts a fall mechanism as a function of injury diagnoses and patient characteristics, derived from 2013 and 2014 Medicare claims as described in the preceding text. The variable "admitted to hospital" indicates whether the observation originated in the MEDPAR or outpatient file. Syncope diagnosis is a dummy variable, which identifies ICD-9 code 780.2 as the principal diagnosis (in which case there must also be a coded injury as a secondary diagnosis to be included in the data). The regression software dropped the indicator for the eighth quantile of total probability from the model because of collinearity. 


\section{Appendix B \\ Discussion of Potential Confounders and Remedies}

We found that dropout among our study population (FFS beneficiaries) was substantially more common among those randomized to the EG (18 percent) than among those randomized to the ACG (7 percent), as was previously reported for the overall study population. The linkage to claims confirmed that dropout could bias study outcomes because we found dropouts to have Medicare costs that were $\$ 235$ per month higher (95-percent $\mathrm{CI}=\$ 98$ to $\$ 371$ ) on average during the 12 months preceding study enrollment. Thus, differential dropout rates between EG and ACG are likely to confound an as-treated analysis but would not affect an intention-to-treat analysis. We also compared the pre-enrollment incidence rate of fall-related ED visits of dropouts and non-dropouts and did not find a statistically significant difference, but our power to detect such a difference was low. Because the analyses of total costs did not use information from the follow-up calls, study dropout after the start of the observation period was not relevant.

An additional type of potential confounding related to differences between the EG and the control groups in the year of enrollment. For the later years of the study, we changed the randomization protocol to increase the proportional allocation to the EG, such that EG enrollment dates were substantially skewed toward the latest years. There are two competing effects here: On the one hand, owing to health care inflation, both baseline and post-enrollment costs would be higher for those assigned to the EG. A subtler problem has to do with the edges of the available data: There was a wave of EG enrollees late in calendar year 2012. Because there was a substantial delay between enrollment and the end of the intervention period (more so for those assigned to the EG), late enrollment meant that a substantial number of EG participants had two-year as-treated observation windows that extended beyond the limits of our available data (which covered claims through calendar year 2014). To remedy this problem, for the two-year (but not the one-year) analyses, we considered only participants who enrolled prior to October 1, 2012, thereby ensuring that most patients in the as-treated group had complete data.

We observe a strong seasonality to study enrollment, with peak enrollment during the months of October and November. From the intention-to-treat perspective, this would not be a source of bias because the intention-to-treat 12- or 24-month observation window for outcomes begins on the study enrollment date for all three groups. In contrast, for the as-treated analysis, this window begins not on the enrollment date but later, at the end of the intervention period, which was delayed more for the EG than for the ACG. Because health care spending is known to vary substantially by season (Jensen and Kronick, 1984), these differences could cause spurious associations.

Just as we compared baseline costs between study participants who completed the intervention and those who dropped out, we also compared baseline costs between the three 
randomization arms. Unexpectedly, we found that average monthly costs in the 12 or 24 months preceding study enrollment were modestly (although not always statistically significantly) lower among those in the EG than among those in the control groups and that this difference was similar in magnitude to the lower costs observed after the intervention in unadjusted analyses. The reason for this difference is not clear, although the increased late allocation to the EG could potentially explain this difference if the long-term care insurance policyholders from whom we drew the study samples changed over time (e.g., if the population were healthier in later years). 


\section{Appendix C Combining Self-Reported Falls with Published Estimates of Cost Savings per Fall Averted}

This is a hypothetical exercise to infer the health care costs that might be avoided if lower rates of self-reported falls in the EG translated into reduced use of health care to treat fall-related injuries, using study data to estimate the proportion of falls that led to injuries and a published estimate of health care costs per injurious fall. This analysis is an alternative, but speculative, framework that overcomes the reduction in statistical power associated with (necessarily) restricting our primary analysis to FFS beneficiaries at the expense of introducing other potential confounders. In particular, this analysis is limited by its reliance on as-treated estimates of the intervention's effect on reducing falls, by the potential inaccuracy of patient recall, and by the uncertain accuracy of the published estimate of health care costs per injurious fall that we use as an input. It might be seen as a best-case (upper-bound) estimate of average health care cost savings that could be expected to result from implementation of a fall-prevention program.

\section{Methods}

Ideally, our cost analysis would take into account program costs for the LifePlans intervention, health care costs due to falls, and costs for time lost from work for both the targeted population and their caregivers. Here, however, we focus specifically on the health care costs associated with falls. (LifePlans has calculated program costs, which we present in the next section.) We chose not to calculate time lost from work because of falls for the population 75 years or older because, according to U.S. Bureau of Labor Statistics, 2015, the labor-force participation rate in 2014 was 8 percent for that population. Given that this labor-force participation rate is relatively small and those in the labor force are likely to be healthier than those not in it, we assume that time lost from work because of falls would account for a very small proportion of total costs. With regard to caregiver costs, Sach et al., 2012, reports that caregivers rarely had to take time off from work to take care of those who fell: A large proportion of people already had caregivers available (either at home or outside the home). For these reasons, we also exclude from this analysis caregiver time lost from work. We do not include the costs of the intervention program. Although LifePlans estimated the total cost at $\$ 500$ per person (Cohen et al., 2015), its estimate includes the cost of quarterly follow-up interviews that might not be incurred in a large-scale implementation of the intervention. 
We calculate the per capita health care cost averted in a certain time period by taking the difference in per capita total health care costs due to falls between the EG and the ACG. The formula for calculating total health care costs due to falls in a certain time period is as follows:

total health care cost due to falls in time period $Y$

$=$ incidence rate (number of falls per person per day)

$\times$ number of days in time period $Y$

$\times$ percentage of falls requiring medical attention

$\times$ health care costs per fall.

Because the intervention's effect could wane over time, we present estimates of potential per capita cost savings from averted falls for the first quarter, the first two quarters combined, the first three quarters combined, and the full four-quarter (one-year) period after the intervention. This approach is also consistent with the Cohen et al., 2015, analysis on cumulative incidence rate. We calculated the cumulative incidence rate for the EG and the ACG, respectively, using the quarterly follow-up interview data that LifePlans collected. Because interviewers asked participants to comment only on whether the most recent fall in the past quarter required medical attention, we cannot know exactly how many falls resulted in medical attention if there were multiple falls in a given quarter. Therefore, we used the subsample of participants with only one fall in each quarter to estimate the percentage of falls that required medical attention.

We searched the published literature for estimates of health care costs per fall requiring medical attention. We used keyword searches combined with snowballing to identify relevant articles. We selected the articles using the following criteria: (1) Estimates for health care costs must be available for the age group of 75 or older (to correspond with the age of patients in the LifePlans sample); (2) the study must have been conducted in the United States; (3) the study must have been conducted in at least two states; and (4) the study must include costs for at least inpatient care, outpatient care, physician office visits, and ED visits. We converted the estimates for health care costs per fall to 2015 U.S. dollars using the Consumer Price Index for medical care (see U.S. Bureau of Labor Statistics, 2015).

\section{Results}

We found only one article (Stevens et al., 2006) with an estimate on medical costs per fall for the population 75 years or older that meets the inclusion and exclusion criteria listed above. The study was a descriptive study to estimate the incidence rate and direct medical costs for fatal and non-fatal fall injuries among the elderly population in the United States using national databases and surveys on nationally representative samples. This estimate includes costs for inpatient care, outpatient care, physician office visits, and ED visits. With adjustment to 2015 U.S. dollars, that estimate of health care costs per fall for the population 75 years or older is $\$ 15,295$. Because Stevens et al., 2006, uses a case crossover approach to estimate fall-related costs (differencing costs 12 months before the fall and costs 12 months after the fall), the cost per fall likely 
represents an upper bound on the true cost of a fall. This is because, in some cases, a fall might simply be a sentinel event for an underlying medical problem rather than the direct cause of the health care costs.

Table C. 1 shows the estimated total health care costs per person over specified time periods and the values for each parameter in the formula for calculating total health care costs. The per capita health care costs averted were $\$ 88$ during the first quarter after the intervention, $\$ 150$ during the first two quarters after the intervention, $\$ 413$ during the first three quarters after the intervention, and \$561 during the first four quarters after the intervention. This implies that the intervention should result in an expected health care cost savings (excluding the intervention's costs) of approximately $\$ 47$ per month.

Table C.1. Parameter Values and Estimates for Total Medical Costs per Person

\begin{tabular}{|c|c|c|c|c|c|c|c|c|}
\hline Group & $\begin{array}{l}\text { Quarter } \\
\text { 1, EG }\end{array}$ & $\begin{array}{l}\text { Quarter } \\
1, \text { ACG }\end{array}$ & $\begin{array}{l}\text { Quarters } \\
1-2, \text { EG }\end{array}$ & $\begin{array}{l}\text { Quarters } \\
1-2, A C G\end{array}$ & $\begin{array}{c}\text { Quarters } \\
1-3, \text { EG }\end{array}$ & $\begin{array}{l}\text { Quarters } \\
1-3, \text { ACG }\end{array}$ & $\begin{array}{c}\text { Quarters } \\
1-4, \text { EG }\end{array}$ & $\begin{array}{l}\text { Quarters } \\
1-4, A C G\end{array}$ \\
\hline $\begin{array}{l}\text { Number of falls per } \\
\text { person per day }\end{array}$ & 0.00103 & 0.00124 & 0.00105 & 0.00117 & 0.00106 & 0.00121 & 0.00110 & 0.00121 \\
\hline $\begin{array}{l}\text { Number of falls per } \\
\text { person per time } \\
\text { interval }\end{array}$ & 0.094 & 0.113 & 0.192 & 0.214 & 0.291 & 0.330 & 0.400 & 0.441 \\
\hline $\begin{array}{l}\text { Percentage of falls } \\
\text { requiring medical } \\
\text { attention }\end{array}$ & 50.99 & 47.57 & 45.97 & 45.95 & 43.76 & 46.7 & 42.5 & 46.84 \\
\hline $\begin{array}{l}\text { Number of falls } \\
\text { requiring medical } \\
\text { attention per person } \\
\text { per time interval }\end{array}$ & 0.048 & 0.054 & 0.088 & 0.098 & 0.127 & 0.154 & 0.170 & 0.207 \\
\hline $\begin{array}{l}\text { Medical costs per } \\
\text { fall, leading to } \\
\text { medical care, in } \\
2015 \text { U.S. dollars }\end{array}$ & 15,295 & 15,295 & 15,295 & 15,295 & 15,295 & 15,295 & 15,295 & 15,295 \\
\hline $\begin{array}{l}\text { Total medical costs } \\
\text { per person per time } \\
\text { interval, in } 2015 \text { U.S. } \\
\text { dollars }\end{array}$ & 732 & 820 & 1,352 & 1,501 & 1,947 & 2,360 & 2,599 & 3,160 \\
\hline
\end{tabular}

\section{Discussion}

For a variety of reasons, these results should be interpreted with caution, and we see them as an upper-bound estimate for potential cost savings. We suspect that the published estimate of cost per fall requiring medical care (Stevens et al., 2006) that we use as an input might overstate true costs, and the conversion to 2015 dollars using the Consumer Price Index for medical care introduces further uncertainty. These estimates are also subject to limitations of the as-treated analytic perspective, discussed earlier. 
Barell, V., L. Aharonson-Daniel, L. A. Fingerhut, E. J. Mackenzie, A. Ziv, V. Boyko, A. Abargel, M. Avitzour, and R. Heruti, "An Introduction to the Barell Body Region by Nature of Injury Diagnosis Matrix," Injury Prevention, Vol. 8, No. 2, June 2002, pp. 91-96.

Centers for Disease Control and Prevention, "ICD Injury Matrices," last updated November 25, 2009. As of September 17, 2016:

http://www.cdc.gov/nchs/injury/injury_matrices.htm

Centers for Medicare and Medicaid Services, "ICD-9-CM Diagnosis and Procedure Codes:

Abbreviated and Full Code Titles," last modified May 20, 2014. As of September 8, 2016 :

https://www.cms.gov/medicare/coding/ICD9providerdiagnosticcodes/codes.html

- "Medicare Provider Analysis and Review (MEDPAR) File," last modified February 18, 2015. As of September 7, 2016:

https://www.cms.gov/Research-Statistics-Data-and-Systems/Files-for-

Order/IdentifiableDataFiles/MedicareProviderAnalysisandReviewFile.html

CMS-See Centers for Medicare and Medicaid Services.

Cohen, Marc A., Jessica Miller, Xiaomei Shi, Jasbir Sandhu, and Lewis A. Lipsitz, "Prevention Program Lowered the Risk of Falls and Decreased Claims for Long-Term Services Among Elder Participants," Health Affairs, Vol. 34, No. 6, June 2015, pp. 971-977.

Crawford, Malik, Jonathan Church, and Bradley Akin, eds., CPI Detailed Report: Data for December 2015, c. 2016. As of September 17, 2016:

http://www.bls.gov/cpi/cpid1512.pdf

Davis, J. C., M. C. Robertson, M. C. Ashe, T. Liu-Ambrose, K. M. Khan, and C. A. Marra, "International Comparison of Cost of Falls in Older Adults Living in the Community: A Systematic Review,” Osteoporosis International, Vol. 21, No. 8, August 2010, pp. 12951306.

Gillespie, Lesley D., M. Clare Robertson, William J. Gillespie, Catherine Sherrington, Simon Gates, Lindy M. Clemson, and Sarah E. Lamb, "Interventions for Preventing Falls in Older People Living in the Community," Cochrane Database of Systematic Reviews, Vol. 9, 2012, art. CD007146.

Jensen, G., and R. Kronick, "The Cyclical Behavior of Hospital Utilization and Staffing," Health Services Research, Vol. 19, No. 2, June 1984, pp. 161-180. 
Neuman, Patricia, Juliette Cubanski, and Anthony Damico, "Medicare per Capita Spending by Age and Service: New Data Highlights Oldest Beneficiaries," Health Affairs, Vol. 34, No. 2, February 2015, pp. 335-339.

Neumann, Peter J., Allison B. Rosen, and Milton C. Weinstein, "Medicare and CostEffectiveness Analysis," New England Journal of Medicine, Vol. 353, No. 14, October 6, 2005, pp. 1516-1522.

Research Data Assistance Center, "Carrier RIF," undated (a). As of September 7, 2016 : https://www.resdac.org/cms-data/files/carrier-rif

_ _ "Durable Medical Equipment RIF," undated (b). As of September 7, 2016:

https://www.resdac.org/cms-data/files/dme-rif

—, "Home Health Agency RIF," undated (c). As of September 7, 2016:

https://www.resdac.org/cms-data/files/hha-rif

— , "Hospice RIF," undated (d). As of September 7, 2016:

https://www.resdac.org/cms-data/files/hospice-rif

_ , "Master Beneficiary Summary File," undated (e). As of September 7, 2016:

https://www.resdac.org/cms-data/files/mbsf

— , "Outpatient RIF," undated (f). As of September 7, 2016:

https://www.resdac.org/cms-data/files/op-rif

_ - "How to Identify Hospital Claims for Emergency Room Visits in the Medicare Claims Data," July 30, 2015. As of September 9, 2016:

https://www.resdac.org/resconnect/articles/144

Sach, Tracey H., Philippa A. Logan, Carol A. C. Coupland, John R. F. Gladman, Opinder Sahota, Valarie Stoner-Hobbs, Kate Robertson, Vicki Tomlinson, Marie Ward, and Anthony J. Avery, "Community Falls Prevention for People Who Call an Emergency Ambulance After a Fall: An Economic Evaluation Alongside a Randomised Controlled Trial," Age and Ageing, Vol. 41, No. 5, 2012, pp. 635-641.

Stevens, J. A., P. S. Corso, E. A. Finkelstein, and T. R. Miller, "The Costs of Fatal and NonFatal Falls Among Older Adults," Injury Prevention, Vol. 12, No. 5, October 2006, pp. 290295.

Tamblyn, Robyn, Tracey Reid, Nancy Mayo, Peter McLeod, and Michael Churchill-Smith, "Using Medical Services Claims to Assess Injuries in the Elderly: Sensitivity of Diagnostic and Procedure Codes for Injury Ascertainment," Journal of Clinical Epidemiology, Vol. 53, No. 2, February 2000, pp. 183-194. 
Tinetti, Mary E., Dorothy I. Baker, Mary King, Margaret Gottschalk, Terrence E. Murphy, Denise Acampora, Bradley P. Carlin, Linda Leo-Summers, and Heather G. Allore, "Effect of Dissemination of Evidence in Reducing Injuries from Falls," New England Journal of Medicine, Vol. 359, No. 3, July 17, 2008, pp. 252-261.

U.S. Bureau of Labor Statistics, 2000 Consumer Price Index detailed report tables: average annual indexes, Tables 1A-23A, undated. As of September 17, 2016 : http://www.bls.gov/cpi/cpid00av.pdf

, "Civilian Labor Force Participation Rate by Age, Gender, Race, and Ethnicity," December 8, 2015. As of September 6, 2016:

http://www.bls.gov/emp/ep_table_303.htm 